\title{
Micro-CT Evaluation of a Novel Technique Used for The Removal of Single Cone Obturated Mesial Roots of Mandibular First Molars Filled with Bioceramic Sealer and Bioceramic Coated Gutta Percha vs Traditional Gutta Percha
}

Ernest Stephen Fragale II

Follow this and additional works at: https://researchrepository.wvu.edu/etd

\section{Recommended Citation}

Fragale II, Ernest Stephen, "Micro-CT Evaluation of a Novel Technique Used for The Removal of Single Cone Obturated Mesial Roots of Mandibular First Molars Filled with Bioceramic Sealer and Bioceramic Coated Gutta Percha vs Traditional Gutta Percha" (2017). Graduate Theses, Dissertations, and Problem Reports. 5620.

https://researchrepository.wvu.edu/etd/5620

This Thesis is protected by copyright and/or related rights. It has been brought to you by the The Research Repository @WVU with permission from the rights-holder(s). You are free to use this Thesis in any way that is permitted by the copyright and related rights legislation that applies to your use. For other uses you must obtain permission from the rights-holder(s) directly, unless additional rights are indicated by a Creative Commons license in the record and/ or on the work itself. This Thesis has been accepted for inclusion in WVU Graduate Theses, Dissertations, and Problem Reports collection by an authorized administrator of The Research Repository @ WVU. For more information, please contact researchrepository@mail.wvu.edu. 
MICRO-CT EVALUATION OF A NOVEL TECHNIQUE USED FOR THE REMOVAL OF SINGLE CONE OBTURATED MESIAL ROOTS OF MANDIBULAR FIRST MOLARS FILLED WITH BIOCERAMIC SEALER AND BIOCERAMIC COATED GUTTA PERCHA VS TRADITIONAL GUTTA PERCHA.

Ernest Stephen Fragale II, D.D.S.

Thesis submitted to the School of Dentistry at West Virginia University in partial fulfillment of the requirements for the degree of

Master of Science

in

Endodontics

Elizabeth Kao, D.M.D., Committee Chairperson

Bryan Weaver, D.D.S., M.D.

Jerry Bouquot, D.D.S., M.S., F.A.C.D.

Keith Hildebrand, D.D.S., M.S.

Department of Endodontics

Morgantown, WV

2017

Keywords: Dentistry, Endodontics, micro-CT, Bioceramic, Brasseler BC Sealer, Single Cone Obturation, Gutta Percha, Bioceramic Gutta Percha, Dentsply TRUShape, Brasseler XP-Shaper Copyright 2017 Ernest Stephen Fragale II, D.D.S. 


\begin{abstract}
MICRO-CT EVALUATION OF A NOVEL TECHNIQUE USED FOR THE REMOVAL OF SINGLE CONE OBTURATED MESIAL ROOTS OF MANDIBULAR FIRST MOLARS FILLED WITH BIOCERAMIC SEALER AND BIOCERAMIC COATED GUTTA PERCHA VS TRADITIONAL GUTTA PERCHA.
\end{abstract}

\author{
Ernest Stephen Fragale II, D.D.S.
}

Introduction: The aim of this study was to evaluate the efficacy of two new to the market 3dimensional serpentine shaped nickel titanium rotary files, XP Shaper and TRUShape, as primary retreatment files for the removal of filling of material from mesial roots of mandibular first molars filled with bioceramic sealer and two different types of gutta percha, bioceramic coated and traditional non-coated cones.

Materials and methods: 40 mesial roots of mandibular first molars were prepared and divided into four groups $(\mathrm{n}=10) .20$ specimens were obturated with single cones of traditional noncoated gutta percha (TGP), EndoSequence Gutta Percha, and 20 specimens were obturated with bioceramic coated single cones (BC), EndoSequence BC Points. Both were sealed with a bioceramic sealer, EndoSequence BC Sealer. Removal of the obturated and sealed gutta percha from the root canals were performed by either the TRUShape (TS) or XP Shaper (XP) files. The efficacy of filling material removal was examined using a micro-computed tomographic scanner. Mean percentages of volume and surface area remaining after the retreatment procedure were analyzed using the Kruskal-Wallis and Mann-Whitney $U$ tests. Canal patency and their correlation with the files and gutta percha were analyzed using Pearson's chi-square test. All tests were set at a significance level of $(p=0.05)$.

Results: The mean percentage volume and surface area of remaining filling material was significantly different $(\mathrm{p}<0.05)$, among all groups tested. The use of XP files in removing BC coated cones, resulted in canals with a mean percentages of $33.98 \pm 5.28 \%$ volume and $61.97 \pm$ $7.17 \%$ surface area of residual material which were significantly different than all the other groups, $(\mathrm{p}<0.05)$. Significant differences were found in the mean percentage of volume and surface area of remaining material when comparing the efficacy of XP to TS $(p<0.05)$, independent of the type of gutta percha used. Finally, there was a significant association between the type of gutta percha used and canal patency $(\mathrm{p}<0.05)$; teeth obturated with TGP cones achieved $65 \%$ canal patency compared to $25 \%$ in those obturated with $\mathrm{BC}$ cones. There appears to be a strong correlation between the type of file used and canal patency $(p=0.0565)$ with $60 \%$ of the TS group regaining canal patency compared to $30 \%$ in the XP group.

Conclusion: Neither of the 3D motion files tested were able to successfully remove $100 \%$ filling material from the canals nor regain $100 \%$ canal patency. However, the TS instrument was found to remove significantly more material independent of the gutta percha used and establish canal patency in $60 \%$ of the roots retreated. Teeth obturated with traditional gutta percha regained canal patency better than those obturated with bioceramic coated gutta percha. The results of this study show that the use of a bioceramic sealer especially in combination with a bioceramic coated gutta percha may make regaining canal patency more difficult. 


\section{Dedication}

I would like to dedicate this body of work to my newborn son, Landon, my wife, best friend and colleague, Amanda, and my parents, Ernie and Tina. From a young age, my parents instilled in me the drive to always want to do better, work harder and most of all, help others. My wife has taught me that we can achieve things together that we would not be able to do separately.

Together, we have made it through a process that neither of us could have imagined being so difficult. While apart we purchased a business, a home and had our first child Landon. Although Landon is only 5 months old, he has already taught me to smile more, relax and most importantly, the true meaning of life. 


\section{Acknowledgments}

I would like to thank Dr. Sean Horan for being a great co-resident and friend. We were able to lean on each other during challenging times throughout our residency training. We did not make it through unscathed, but we did make it through stronger. I look forward to sharing in the treatment of our home state's population. One of these days we will be able to have a glass of wine and laugh about our two and half years.

I would like to thank Dr. Mehran "Ron" Malenkapour for his humor, wit, kindness and willingness to always lend a hand. Without your friendship and help throughout this project, I may have gone crazy. You kept me on task and pushed me through the frustrating times. It has been great to see how far you've come first as a dental student and now as an endodontic resident. You are going to be a great clinician not only because of your clinical skills and knowledge, but because of your compassion!

I would like to thank Dr. Elizabeth Kao for her humor, knowledge, insight and flexibility with this project. I could not have done it without your ideas and help!

I would like to thank Dr. Jerry Bouquot for his project ideas and insight into the process of designing and executing a thesis project.

I would like to thank Dr. Keith Hildebrand for being a great mentor, advocate, friend and listener. I hope that we get to play some more golf in the future but that you will find some time to practice as well!

I would like to thank Dr. Leigh Speer for his guidance and mentorship. Without you, there would be no graduate endodontic program. Thank you for taking a chance on WVU and allowing Sean and I to be a part of the reconstruction of our program.

I would like to thank Dr. Bryan Weaver for his tremendous level of expertise in Medicine and allowing me to pick his brain about cases other than those involving endodontics. Thank you for sharing your knowledge and always accommodating other residents that are not a part of your OMFS program.

I would like to thank Chris Waters for his guidance throughout the completion of my thesis. Without his research experience and resources, Sean and I would have been lost.

I would like to thank Sarah McLaughlin and Karen Martin for their guidance with the micro-CT scanning and analysis. I would not have been able to design this project if I had not found your department and skills! Thank you!

I would like to thank Dr. Tom Borgia for him accepting me into the program and his insight in the endodontic topics.

I would like to thank Dr. Christina DeBiase for her guidance through our residency and most importantly, our advocate for program changes. 
I would like to thank the current residents of WVU Endodontics. You have been left with a different residency than Sean and I walked into. Take the changes that he and I advocated for and make them better. Always ask "why" and challenge the status quo. In the end, we will all be connected not just by our profession, but how we got there, WVU. Make it something you will be proud of when you look back on your time in Morgantown.

Thank you to the AAE Foundation / Dentsply Innovation in Research Grant for giving me the opportunity and support to design and complete a study that otherwise could not have been funded without your assistance. 


\section{Table of Contents}

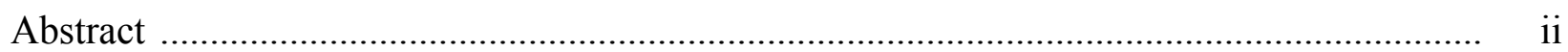

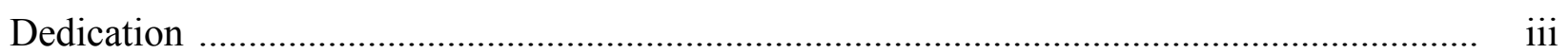

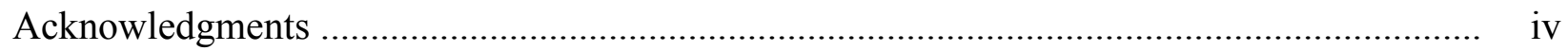

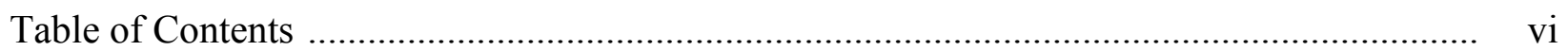

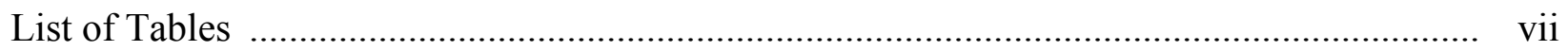

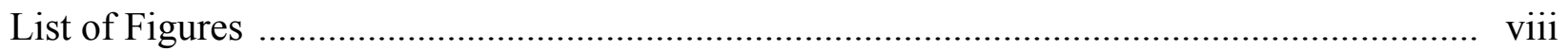

List of Symbols, Abbreviations or Nomenclature ………................................................. $\mathrm{x}$

Chapter I

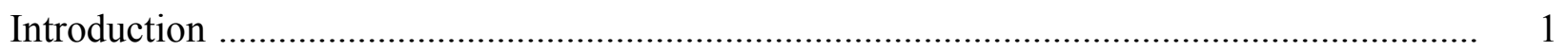

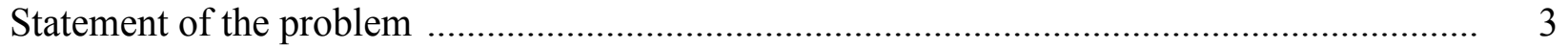

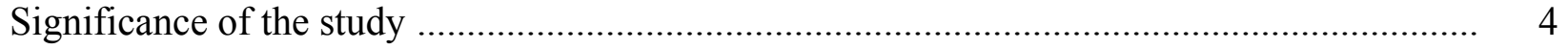

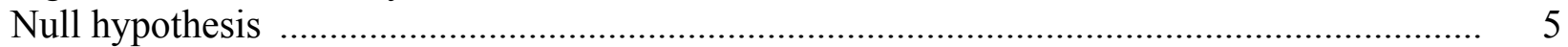

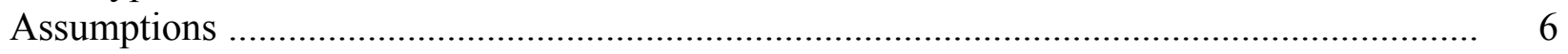

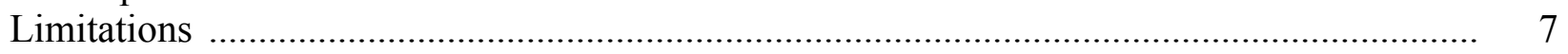

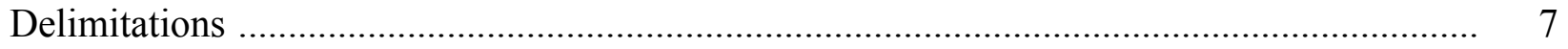

Questions to be answered .......................................................................................... 8

\section{Chapter II}

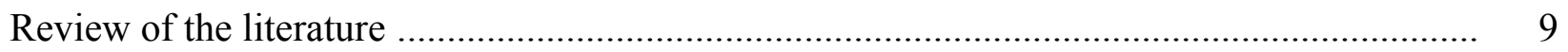

\section{Chapter III}

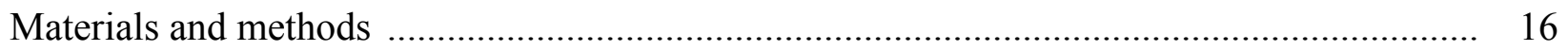

Statistical analysis ............................................................................................... 34

\section{Chapter IV}

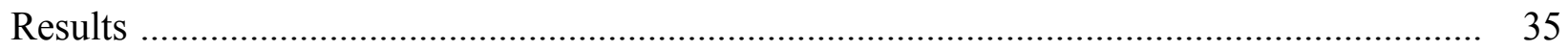

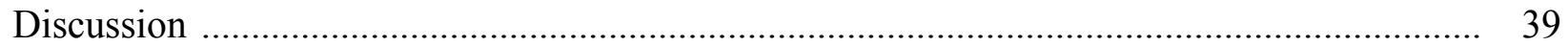

Chapter V

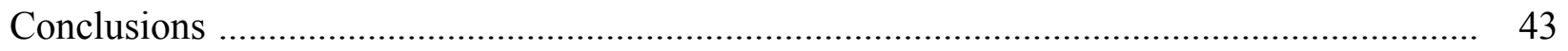

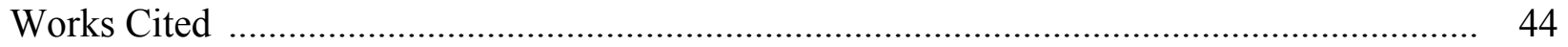




\section{List of Tables}

Table 1 Data generated by CTAn software of obturated root (object volume and object surface)

Table 2. Data generated by CTAn software of retreated root (object volume and object surface)

Table 3. Raw data for obturated and retreated specimens as object volume and object surface from CTAn software

Table 4. Number of canals patent

Table 5: Mean percentage of volume and surface area remaining

Table 6: Bonferroni adjusted p-values for the pairwise comparison

Table 7: Mean percentage of volume and surface area remaining

Table 8: Mean percentage of volume and surface area remaining

Table 9: Percentage of patent canals between gutta percha groups 


\section{List of Figures}

Figure 1. 170 extracted mandibular molars . .............................................................. 16

Figure 2. Example of selected tooth anatomy ......................................................... 16

Figure 3. Radiograph for each tooth ...................................................................... 17

Figure 4. Sectioned mesial root and conservation of remaining tooth structure $\ldots \ldots \ldots \ldots \ldots \ldots \ldots . . . . . . . .17$

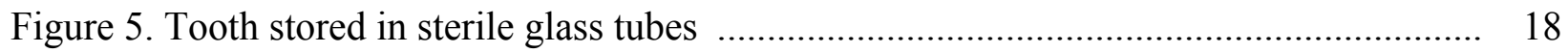

Figure 6. Dentsply ProGlider NiTi file .................................................................. 19

Figure 7. Dentsply ProMark Rotary Motor ............................................................. 19

Figure 8. 8:1 Electric Hand Piece ........................................................................ 19

Figure 9. Dentsply ProTaper Gold S1 NiTi file ....................................................... 20

Figure 10. Dentsply Vortex Blue 30.06 NiTi file ...................................................... 20

Figure 11. Dentsply QMix 2in1 Final irrigation solution ........................................... 21

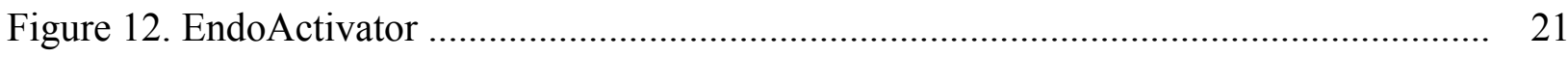

Figure 13. Brasseler EndoSequence Gutta Percha Points (TGP) ..................................... 22

Figure 14. Brasseler EndoSequence BC Points (BC) ............................................... 22

Figure 15. Brasseler EndoSequence BC Sealer ...................................................... 22

Figure 16. Wrapped mesial root and damp cotton rolls ............................................. 23

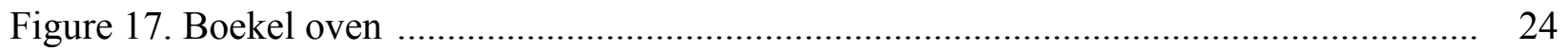

Figure 18. Temperate at 37 degrees Celsius ............................................................ 24

Figure 19. Dentsply TRUShape 30.06 NiTi file ....................................................... 25

Figure 20. Brasseler XP Shaper NiTi file ........................................................... 25

Figure 21. 10 K-files through canal foramen ......................................................... 27

Figure 22. Close up of hand files illustrating canal patency ......................................... 27 


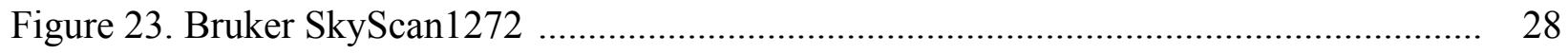

Figure 24. Animal Research Facility _....................................................................... 28

Figure 25. Mesial root on micro-CT crucible …………................................................... 29

Figure 26. Software station for data analysis .................................................................. 29

Figure 27. Example of a micro-CT image and slice of obturated root from DataViewer software

Figure 28. Example of micro-CT image and slice of retreated root from DataViewer software

Figure 29. Example of 3D reconstruction of obturated root by CTvol software ..................... 31

Figure 30. Example of 3D reconstruction of retreated root by CTvol software ..................... 31 


\section{List of Symbols, Abbreviations or Nomenclature}

Nickel-Titanium - NiTi

TruShape file - TS

XP Shaper file - XP

Traditional Gutta Percha - TGP

Bioceramic Gutta Percha - BC

Microcomputed tomography - micro-CT

Cold Lateral Condensation - CLC

Continuous Wave Condensation - CW

Warm Vertical Condensation - WVC

Millimeters - mm

Mesio-buccal - MB

Mesio-lingual - ML

Sodium Hypochlorite $-\mathrm{NaOCl}$

Working Length - WL

Institutional Review Board - IRB

Newton centimeters $-\mathrm{Ncm}$

Directions for Use - DFU 


\section{Chapter I}

\section{Introduction}

Complete removal of gutta percha from well obturated endodontically treated teeth have proven to be a challenge in the past. The advent of new nickel titanium instruments (NiTi), chemical solvents, and heat have aided in the complete removal, but still fall short of the goal of completely eliminating all remnants of obturation material $(1,2,3,4)$. Failure to remove all obturation and sealer materials greatly hinders the success of endodontic retreatment by not allowing chemical disinfectants to reach all areas occupied by residual bacteria resulting in recurrent or persistent infection $(5,6)$. Modern day obturation techniques such as warm vertical compaction and carrier based techniques have increased effectiveness of a 3-dimensional fill into fins and irregularities of the canal system but have also made removal in these areas more difficult when a retreatment is needed due to persistent apical periodontitis $(6,7,8)$.

Over the past decade, NiTi instruments have greatly increased the efficiency and effectiveness of obturation material removal compared to hand files during the retreatment procedure $(12,13)$. Despite the advancements of NiTi used for the removal, research shows that complete elimination of material is still not always achieved, leaving behind area likely inhabited by bacteria contributing to infection and symptoms $(1,2,3,4)$. Traditional files have either a constant or variable taper that produces a center of axis in the middle of the file which creates a circular cutting path. This cutting motion does not enable the file to touch all surfaces of the root canals that may not be perfectly round $(14,15,16)$. Two new NiTi files with 3D motion were developed recently and are available for commercial use, TRUShape file (Dentsply, Tulsa, OK, USA) and XP Shaper file (Brasseler USA, Savanah, GA, USA). The innovative 3D motion allows these files to adapt to the irregularities in the canal that a traditional cylindrical file cannot reach. This is accomplished by a file design incorporating a S-shaped curve from the tip of the instrument to the shank. This creates a unique motion in the canal allowing more surface area to be touched thus theoretically eliminating more tissue and bacteria in necrotic teeth. This 3D instrumentation technique can offer a possible advantage to removal of gutta percha and sealer in retreatment cases compared to standard tapered instruments previously described by touching more areas filled with gutta percha and sealer than traditional NiTi files (17).

While both files have shown evidence of obturation material removal when utilized as supplementary files following gross removal of obturation materials with traditional shaped NiTi rotary files $(18,19,20)$, our study will attempt to use the files as the primary retreatment files. This novel technique is based on the manufacturer's clinical videos (Brasseler USA) for XP Shaper in the retreatment of an acrylic maxillary first molar obturated with BC Sealer and bioceramic coated gutta percha (21). While Dentsply does not have any published instructions for the use of the TRUShape file in a retreatment procedure, we completed a pilot study operating the file at 900 RPM as suggested by Dr. Clifford Ruddle for NiTi instrumentation retreatments (105). The pilot study used mandibular anterior teeth to test the higher speeds and file resistance to fracture before proceeding with the study design for mesial roots of mandibular molars.

Newer sealers and gutta percha released in the past several years such as Brasseler's BC Bioceramic Sealer and bioceramic coated gutta percha have emerged with claims of superior sealing capabilities due to zero shrinkage compared to other sealers such as resin and zinc oxide eugenol based products. Similar to other bioceramic materials used in dentistry, bioceramic sealer 
ultimately results in a hydroxyapatite precipitant formation when the main components, tricalcium silicate and calcium phosphate, absorb moisture from the tooth. The properties of this new sealer and formation of hydroxyapatite also allow a chemical and mechanical bond to dentinal walls as well to the new bioceramic coated gutta percha $(9,10)$. This bond could be advantageous for sealability of the obturated canals but could make removal very difficult if retreatment is necessary. Brasseler recommends a single cone obturation technique with their new bioceramic sealer, independent of the type of gutta percha used (9). This is contrary to the warm vertical or cold lateral obturation techniques taught in dental schools for the past 40 years. These traditional obturation techniques rely on the fill of the gutta percha against the canal wall by the placement of multiple cones or thermoplastic gutta percha whereas the single cone technique relies on the sealer to fill any area not occupied by the single gutta percha cone (11).

Mesial roots of mandibular molars have historically been used for studying the effectiveness of files due to their anatomic complexity compared to single rooted anterior teeth or single-rooted premolars $(19,22,23)$. Also, a large portion of endodontic retreats occur on mandibular molars, so new techniques that could possibly be implemented into clinical use need to be tested on teeth that have the toughest roots to negotiate (24).

In order to quantify the amount of residual filling material left in each of the four groups, micro-computed tomography (micro-CT) will be used to produce high resolution 3-dimensional data from hundreds of 2-dimensional slices for each root. The mean percentage volume and mean percentage surface area of remaining filling material will be calculated from the resulting images by comparing the material left in the canals to that of the obturated canals of the same roots. Root canal patency will also be observed clinically with a stainless-steel hand file. The results will be reported and analyzed for any statistical significance. 


\section{Statement of the Problem}

It is unknown if the new 3D motion NiTi rotary instruments can be used as primary retreatment files. One manufacturer, Brasseler, has published videos on its website detailing the retreatment process with their respective XP Shaper file. It is also unknown if retreatment with the bioceramic coated gutta percha cones and bioceramic sealer would be more difficult to remove than that of traditional gutta percha and bioceramic sealer. The objective of this study was to determine if the novel technique of using two new 3D motion instruments, TRUShape and XP Shaper, as primary gutta percha removal instruments, would be effective and efficient of the removal of two different gutta percha cones coated with bioceramic sealer in mandibular mesial roots assessed by micro-CT analysis. 


\section{Significance of the Study}

There is evidence that using 3D motion NiTi files can increase the amount of radicular canal contact during the initial instrumentation of root canals, thus improving the effective removal of bacteria and diseased dentin. This same principle could be applied to the removal of gutta percha during the retreatment procedure. There are a few new studies showing the capability of 3D files as supplemental instruments for the aid in removal of gutta percha but only one showing the TRUShape file used as a primary retreatment file. The results of our study will show if either manufacturers' respective 3D motion files can effectively remove gutta percha as a primary instrument, thus allowing clinicians to save time, reduce the number of files used, and be more efficient and effective at the retreatment procedure. The results will also shed light on the difference in retreatability and restoration of patency in bioceramic sealed canals obturated with traditional gutta percha vs those with the bioceramic coated gutta percha cones. 


\section{Null Hypotheses}

There is no statistically significant difference of the amount of remaining obturation material in mesial roots of mandibular first molars between the type of file used for the removal; TRUShape and XP Shaper.

There is no statistically significant difference of the amount of remaining obturation material between bioceramic coated gutta percha with bioceramic sealer vs traditional gutta percha with bioceramic sealer.

There is no statistically significant difference between the type of gutta percha and file used for the achievement of regaining canal patency during retreatment. 


\section{Assumptions}

1. The mesial roots of mandibular first molars contain varied canal anatomy and curvature.

2. The mesio-buccal and mesio-lingual canals in mesial roots of mandibular first molars are similar in nature.

3. 3-dimensional moving NiTi instruments make more intimate contact with the radicular canal surface compared to a fixed standard taper NiTi instruments.

4. The more effective removal of gutta percha from the radicular canals means that more bacteria are being removed from the canals.

5. Bioceramic sealer is more difficult to remove than traditional sealers such as zinc oxide eugenol and resin based.

6. The single cone obturation technique will fill more canal irregularities with sealer than gutta percha compared to warm vertical and lateral condensation techniques.

7. Micro-CT analysis is an accurate and reliable tool for the measurement of remaining gutta percha in the radicular canals during the retreatment procedure. 


\section{Limitations}

1. There is a relatively small sample size for each group.

2. This is an in-vitro study that may or may not translate to the same results as an in-vivo study.

3. The lengths of the mesial roots in the study were not standardized resulting in variability of the length and amount of obturation material.

4. The root anatomy between mesial roots in each group are varied in curvature and complexity.

5. The root configuration is not the same between each mesial root.

6. There is variability in canal preparation, obturation, sealing, and removal technique.

7. There is variability in the interpretation of patency.

8. There are no directions for use (DFU) specific to the retreatment procedures available for the $3 \mathrm{D}$ files used in this study.

\section{Delimitations}

1. Every tooth was microscopically examined for complete root growth.

2. Every tooth was radiographed in a bucco-lingual view with a digital sensor for canal curvature evaluation.

3. All mesial roots were selected with curvature less than 40 degrees.

4. All mesial roots were accessed, instrumented, obturated and retreated by the same clinician to help insure consistency through the study.

5. All canals were instrumented to the same size and taper and obturated with a corresponding gutta percha.

6. All roots were stored together in $100 \%$ humidity for the same amount of time.

7. Micro-CT offers an accurate form of measurement allowing for a non-destructive evaluation of the roots.

8. All teeth were scanned with the same parameters, settings and ambient temperature for obturation and retreatment scans.

9. The number of slices to be analyzed was recorded and kept consistent for the obturation scan and retreatment scan for consistency of the amount of root evaluated. 


\section{Questions to be answered}

1. Will either file, TRUShape or XP Shaper work as a primary instrument for adequate gutta percha removal?

2. Will there be any difference in the residual filling amount between XP and TS files?

3. Will there be a difference in the residual filling amount between the types of gutta percha, $\mathrm{BC}$ and TGP?

4. Will there be a difference in the achievement of canal patency between the two files, XP and TS, and between the two types of gutta percha, BC and TGP? 


\section{Chapter II}

\section{Review of literature}

1. Single cone obturation compared to alternative obturation techniques.

2. Bioceramic sealer: properties, workability, sealability, biocompatibility.

3. Retreatability of bioceramic sealers.

4. Bioceramic gutta percha compared to traditional gutta percha.

5. Persistent apical periodontitis and the importance of bacterial reduction.

6. Removal of gutta percha and sealer with various endodontic files.

7. 3D motion files: Brasseler XP Shaper and Dentsply TRUShape.

\section{Micro-CT analysis.}

\section{Single cone obturation compared to alternative obturation techniques.}

Various root canal obturation techniques have been employed throughout the years. While each clinician has his or her favorite, cold lateral condensation, warm vertical compaction and single cone obturation are three techniques that are taught by most U.S. dental schools and Endodontic residency programs. Cold lateral condensation and warm vertical condensation techniques have the same goal in mind, to attempt to get a maximum fill of gutta percha into the root canal while utilizing the gutta percha as a barrier for penetration of new bacteria. Both have also been proven to be successful and are tried and true techniques. Single cone obturation relies on the endodontic sealer placed around the gutta percha to fill any empty space that the single cone does not adapt well to. $(11,25)$

Cold lateral condensation (CLC) is completed by placing a thin layer of endodontic sealer on the "master gutta percha cone" that fits the most apical portion of a prepared root canal. "Accessory gutta percha cones" are then seated alongside of the master cone until a tight fit occurs. Additional accessory cones are added following the placement of a "spreader" into the previously placed cones. The spreader placement condenses the previously placed gutta percha cones in a lateral direction, thus making more space for additional cones. Once the spreader cannot be advanced into the gutta percha, the obturation of the root canal is complete. The goal of this technique is to force pliable gutta percha in a lateral direction to give a tight packing of the gutta percha. $(11,25)$

Warm vertical condensation (WVC) and continuous wave obturation (CW) use the same techniques as lateral condensation in regard to the placement of the master cone. Once the master cone is seated, a heat element is placed into the master cone to an approximate distance of 4$5 \mathrm{~mm}$ from the working length. The heated element is left in place to allow for 5-10 seconds of cooling to the gutta percha around the heat element. Upon removal of the heat element, the coronal portion of the gutta percha is removed while the warm apical plug remains in place. A "plugger" is then placed into the canal to "condense" the softened apical plug of gutta percha in apical and lateral directions. Lastly, thermoplastic gutta percha is added to the root canal on top 
of the apical plug in small increments until the canal orifice is reached. The advantage of $\mathrm{WVC} / \mathrm{CW}$ over CLC is the condensation of the warm gutta percha. This allows the gutta percha to be pushed into canal irregularities and maximize the amount of gutta percha filled into a root canal. $(11,25)$

With the widespread use of rotary NiTi instruments and matching taper gutta percha, single cone obturation technique has become popular (26). Single cone obturation (SC) is completed by placing a single gutta percha cone that matches the size and taper of the master apical file $(11,25)$. The sealer is typically placed by either syringing it into the root canal prior to placement of the cone or by coating the master cone prior to placing it into the canal (9). Once the single cone is placed into the canal, obturation is complete. Since there is no lateral condensation used or warming of the gutta percha to be able to condense it laterally and apically, the sealer plays an important role in filling any spaces that the gutta percha cone cannot $(11,25)$.

Several studies have been designed to compare the previously described techniques. Iglecias et al. recently showed in her micro-CT study that there was no significant difference between WVC and SC in terms of total percentage volume of voids (27). Alshehri et al. also completed a micro-CT evaluation of the difference between single cone obturation and warm vertical condensation. His study revealed that there was no significant difference in the quality of obturation at three different levels of the root: apical, middle and coronal sections (28). In a 2012 study Robberecht tested the difference between single cone obturation and warm condensation by microscopic examination of voids in the gutta percha and the ability to fill lateral canals. He found in his sections that the warm technique was superior to the single cone technique; with the warm condensation group having statistically less voids than that of the single cone group and a better quality of obturation (29).

When comparing single cone obturation to cold lateral techniques, Tasdemir et al determined that a single cone technique yielded a significantly greater percent of gutta percha filled area at a distance of $2 \mathrm{~mm}$ from the apex than that of cold lateral obturated samples. His results suggest that the single cone technique with tapered gutta percha cones may yield better results than lateral condensed cones (30). Gordon et al also found in his 2005 study that single 0.06 taper gutta percha filled canals were similar to cold lateral obturated canals in their overall quality of obturation. He also showed that in curved canals over 58 degrees, there was significantly more gutta percha in the apical portion with the single cone technique compared to the cold lateral condensation technique (26).

In regard to the effect of obturation technique on bioceramic sealers ability to penetrate into the dentinal tubules, Jeong et al found no difference between single cone and warm vertical obturation via confocal laser microscope analysis. The pressure derived from warm vertical condensation did not enhance penetration depths of bioceramic sealer thus the penetration into the dentin tubules occurred independent of the obturation technique (31).

\section{Bioceramic sealer: properties, workability, sealability, biocompatibility.}

In order to improve the marginal sealing properties of the root canal system, hydrophilic root canal sealers such as bioceramic sealers have been introduced. This is in contrast to the traditional root canal sealers such as resin and zinc oxide eugenol sealers that are hydrophobic in 
nature (32). Due to the moist working environment, a hydrophilic sealer is a welcome improvement.

Most bioceramic sealers come in a premixed syringe that allows precise dispensing of a desired amount compared to having to mix a catalyst and base and wasting the excess amount not used. Bioceramic sealers are nanoparticle in size. This, in combination with the hydrophilic properties, allow for great flowability into the moist dentinal tubules and canal irregularities. Another great property of bioceramic sealer is zero shrinkage upon setting. This enables gap-free interfaces between gutta percha $\&$ sealer and sealer $\&$ dentin $(10,32)$. This is in direct contrast of resin and zinc oxide sealers used in combination with cooling thermoplastic gutta percha. Once the cooling of these materials occurs, a microscopic gap can be formed in the interfaces allowing bacteria to contaminate the entire canal system (34).

With the ultimate goal of obturation being to establish a hermetic seal that prevents reinfection, bioceramic sealers can potentially provide a great solution. Most endodontic failures occur as a result of leakage of bacterial invasion from treated and filled root canals into the periapical tissues (35). The leakage can occur between the root canal filling, sealer and dentin after root canal treatment. Endodontic material should be placed permanently to block the pathways of communication between the root canal system and its surrounding tissues to ensure long term success (36). All of these factors have led to the development of filling materials that poses characteristics such as: non-toxic, insoluble in tissue fluids, dimensionally stable, antibacterial, conductive to hard tissue deposition, biocompatible, radiopaque and easy to handle $(37,38)$. The challenge is to be able to develop an ideal material that embodies all of these properties.

Bioceramic materials were first introduced as retrograde repair material in the 1990s and later as sealer and coatings of gutta percha cones $(39,40,41)$. Its biocompatible nature makes it ideal for human tissue. As stated previously, bioceramic materials are biocompatible, non-toxic, non-shrinking and chemically stable in a moist environment. This allows the material to form a hydroxyapatite layer that can reinforce the bond between dentin and bioceramic material (42).

EndoSequence BC Sealer (Brasseler USA) is an example of a bioceramic endodontic sealer. It comes in a premixed syringe that contains the following "ingredients": zirconium oxide, tricalcium silicate, dicalcium silicate, colloidal silicates, calcium phosphate monobasic, and calcium hydroxide $(10,33)$. These materials are hydrophilic in nature therefore it favors the presence of moisture for a complete set. The absorbed water from the external environment such as saliva and dentinal tubules mixes with the tricalcium silicate and calcium phosphate in the material to form a crystalline structure of calcium silicate, known as hydroxyapatite (43). The hydroxyapatite formation can reinforce the bond between the dentinal wall and the sealer (43, 44). Due to the water content of the dentin tubules, the moisture needed for the set of the BC Sealer is provided naturally. The manufacturer states a setting time of four hours in natural physiological environments, and up to 10 hours in dry canals. Some studies have shown that invitro setting times to be as high as 72 hours for an initial set and 240 hours for a final set (43).

When comparing the difference in bioceramic sealers to resin sealers such as Dentsply's AH Plus, Celikten et al discovered in his micro-CT study that there was no difference in the void formation between the sealers with the single cone technique. All sealers produced voids with statistically significant less voids in the apical portion of the roots compared to the middle and coronal portions (45). Guinesi took the evaluation of bioceramic sealer's quality of root canal 
filling one step further by determining if the placement technique of the sealer caused any differences. She determined that placing the sealer into the canal prior to seating the single master cone with a file resulted in the highest filling volume in compared to placing with the sealer with the master cone or lentulo spiral (46). Hedge and Arora compared the sealability via a glucose leakage study in 2015 on single rooted extracted teeth. They found bioceramic sealer placed with a single cone had superior sealing ability compared to a lateral condensation technique with resin sealer or a single cone technique with a resin sealer (32).

Variability exists in the bonding behavior of the BC Sealer in different studies. A recent study by Nagas showed that BC Sealer presented the highest bond strength when compared with several resin based sealers as well as another brand of bioceramic sealer $(47,48)$. However, another three separate studies showed BC Sealer has a similar bond strength to AH Plus (49, 50, 51). Only one study shows BC Sealer having a significantly lower bond strength than AH Plus (52). Tasdemir proved in his recent 2014 research study that the type and amount of drying after irrigation of the root canal can affect the bond strength of bioceramic sealers. He found that canals dried with only 1 paper point had a significantly stronger bond strength with BC Sealer compared to groups dried with multiple paper points or ethanol (32).

It's unclear if the solubility of the sealers can influence the sealing properties of BC Sealer. A study by Borges et al shows that BC Sealer recorded higher solubility than AH Plus whereas a more recent study by Erahan showed no significant difference between BC sealer in AH Plus in solubility $(53,54)$.

Bioceramic material has been shown to be highly biocompatible with human tissues. In several studies conducted by Willershausen and Mukhtar, BC Sealer has been shown to be no more cytotoxic than other commonly used sealers such as resin and zinc-oxide eugenol $(55,56)$. In their studies, BC sealer was non-cytotoxic after at 72 and 96 hour setting times, along with the ability of human gingival fibroblasts to attach to and spread over the surface of BC Sealer. While unset BC Sealer has been shown to be mildly cytotoxic, this has been shown by Zoufan to be less than that of resin sealers like AH Plus (57). Contrary to these studies, Loushine found that cytotoxicity of BC Sealer to be higher than AH Plus with no reduction over a 6-week time span (43). Despite the differences in these results, Zhang found that BC Sealer showed higher hard tissue deposition capability than AH Plus over a 7-day time period (58). Finally, in 2016, an invitro 3D collagen scaffold fibroblast cell culture study by Silva concluded that both resin and bioceramic root canal sealers were biocompatible in nature by comparing the two sealers reaction to exposed type I collagen (59).

The antibacterial properties of sealers are important in that any residual bacteria that may not have been eradicated by chemico-mechanical means, should be addressed by the permanent placement of sealers. The antimicrobial effect of BC Sealer is due to the high $\mathrm{pH}$ and active calcium hydroxide release (10). In Scelza's research, he showed that bacterial reduction occurred for up to 7 days after BC placement (60). In Wang's 2014 study, he proved that BC Sealer had antibacterial effects against $E$. faecalis in the dentinal tubules killing $18 \%, 35 \%$ and $45 \%$ bacteria in 1, 7 and 30 days respectively. Wang also showed that BC Sealer and AH Plus sealers had better antimicrobial properties than that of zinc oxide-eugenol sealers (61). 


\section{Retreatability of bioceramic sealers.}

Due to the precipitate formation of hydroxyapatite from bioceramic material, BC Sealer can be more difficult to retreat (10). While this hydroxyapatite deposition is good for the sealing of the gutta percha, the removal can be somewhat problematic $(33,62)$. Hess demonstrated in his 2011 study that BC Sealer obturated canals with single cones either short of the working length or to the working length, were unable to achieve complete canal patency $70 \%$ and $20 \%$ respectively (33). An additional micro-CT study by Oltra et al comparing the retreatability of $\mathrm{BC}$ Sealer and AH Plus showed that there was significantly less residual root canal filling material in the AH Plus group than that of BC Sealer. Furthermore, he demonstrated that only $14 \%$ of teeth obturated with BC Sealer could regain patency (62). These results differ from a 2015 study by Kim where he found that BC Sealer and AH Plus have similar retreatment efficacy when establishing canal patency and time taken for retreatment. All samples were able to have canal patency re-established in his study (63). Ersev also noted in his 2012 study that when using radiographic analysis and ProTaper D-Series rotary instruments for the retreatment of single cone obturation with $\mathrm{BC}$ Sealer, there was no difference in amount of material remaining in the canal compared to AH Plus with a single cone (64).

\section{Bioceramic gutta percha compared to traditional gutta percha.}

Bioceramic coated gutta percha is a relatively new concept and product line. It was developed by Brasseler USA to go along with their BC Sealer. Due to its recent introduction, there is little to no research on bioceramic coated gutta percha cones specifically. The idea behind the concept is that the gutta percha can be coated with the same bioceramic nanoparticles that are found in BC Sealer. With the gutta percha being coated, in theory, when the BC Sealer sets, it will form a stronger bond between the gutta percha and sealer interface than that of noncoated gutta percha and bioceramic sealer (65). While this could improve bond strength, there is no evidence if this will improve the outcomes of endodontic treatment or make removal of the filling system more difficult. There is one study available that compared the bond strength and fracture resistance of roots obturated with $\mathrm{BC}$ Sealer and BC coated gutta percha. In the study, Ghoneim found that the roots obturated with $\mathrm{BC}$ Sealer and $\mathrm{BC}$ gutta percha were significantly more resistant to fracture compared to other groups of gutta percha and sealer (66). A recent study by Eltair evaluated the interface between gutta percha and two types of sealer using scanning electron microscopy. The results showed no difference in the interfacial gap between resin sealer and traditional gutta percha compared to bioceramic coated gutta percha and $\mathrm{BC}$ sealer. While this study does not test the bond strength, it does show that the coated cone appears to play no significant role in the gap thickness between the gutta percha and sealer (67).

\section{Persistent apical periodontitis and the importance of bacterial reduction.}

Teeth with persistent apical periodontitis or teeth that have become newly contaminated pose a challenge for clinicians. The persistent apical inflammation has been correlated to bacterial byproduct present in the canal that make their way throughout the length of the root canal system $(68,69)$. The goal of retreatments on these teeth is to remove as much, if not all, of the previously placed gutta percha. This is for two reasons; First, there is bacteria attached to the 
gutta percha, that if left behind, could contribute to a reinfection. Secondly, if the gutta percha is not removed from the canal wall, then the irrigation used for disinfection cannot reach the dentinal tubules, where infiltrated bacteria are harboring $(70,71)$.

\section{Removal of gutta percha and sealer with various endodontic files.}

Mechanical removal of gutta percha is routinely performed by using hand files, rotary instruments, ultrasonic tips, solvents and heating devices (72-75). NiTi instruments are often the clinicians first choice for the removal of previously treated teeth for their efficiency and speed. However, in some canals, such as molars and multi-rooted premolars, canal irregularities make it difficult to remove all of the obturation material. When comparing obturation material removal, Rodig showed in his study that NiTi files were both faster and more effective than hand files (4). Irrespective of the type of file or device used for obturation material removal, there is always one common theme, no instrument has shown complete removal of gutta percha from the root canal system, particularly in the apical portion of the root $(76,77,78)$. The significance of leaving material behind in the canal was previously discussed in number 5 of this section.

\section{3D motion files: Brasseler XP Shaper and Dentsply TRUShape}

The past year has shown the introduction of two new files to the market, Brasseler XP Shaper file and Dentsply's TRUShape file. Both files occupy a new class of files, 3D motion. A traditional NiTi rotary file with a standard or variable taper design moves in one plane of motion consistent to the files geometrical construction, leaving an estimated $80 \%$ of canal walls untouched. The only way to increase cutting radius is to brush the file in different directions, however a high percentage of walls still remain untouched $(16,79)$. The new 3D motion files have attempted to improve the instrumentation of an imperfectly round root canal by constructing a file that moves in a non-linear motion.

The XP Shaper file is manufactured from a super elastic and flexible nickel titanium referred to as MaxWire alloy. The file has a tip size of ISO \#27 with a 0.01 taper across the serpentine shape of the instrument. The manufacturer claims that the MaxWire alloy allows the file to expand from its original size to enlarge the canal to at least 30.04 while addressing the natural 3D structure of the root canal space. They also claim that the booster tip of the instrument enables the file to enlarge the canal from an apical size of \#15 to \#30 in a single step without the need of the traditional incremental increase in apical size $(17,80)$. At this time, there is only one study that has tested the new file's shaping ability compared to that of a standard taper NiTi rotary file such as Vortex Blue. Azim's 2017 micro-CT study showed that XP Shaper significantly increased the canal volume, surface area, and the amount of dentin removed. It also had significantly less untouched walls compared to the Vortex Blue file. There was also a strong correlation that showed more debris removal with the XP Shaper file. These results show that the XP Shaper and its unique MaxWire metallurgy can expand beyond its core size to adapt to the anatomy of the root canal space (17).

The TRUShape file has a multi-planar S-shaped curve from the tip of the instrument to the beginning of the shank, thereby creating an envelope of motion with the aim of increasing the percentage of walls touched during instrumentation. The file comes in four tip sizes with 0.06 
taper: 20.06, 25.06, 30.06, 40.06 with a triangular cross section. The ability of the TRUShape instrument to compress into smaller canal spaces and return to their original shape as the canal irregularities are encountered, gives it the ability to increase the amount of canal walls instrumented (81). A micro-CT study by Guimaraes in 2017 comparing the shaping ability of TRUShape files to a traditional taper file showed a significant difference in the amount of uninstrumented areas for the traditional file. However, this difference was not observed in the apical portion of the root canal (82). Another study confirmed the difference in untreated canal surfaces by showing with micro-CT analysis that in mesial roots of mandibular molars, TRUShape files had significantly less untouched surfaces compared to Vortex Blue instrumented canals (83). Finally, a recent micro-CT study in 2016 evaluated TRUShape files' ability to retreat single cone obturated mandibular canines compared to a standard taper reciprocating file. This study concluded that the TRUShape file was slower compared to the reciprocating instrument when used for the retreatment procedure. The study also showed that neither instrument differed significantly from each other on the amount of remaining root canal filling material left in the canals (84).

\section{Micro-CT analysis.}

Researches wanting to assess the teeth in a scientific manner when comparing before and after instrumentation studies were limited to radiographic interpretation. While this can be helpful, there is no way to correctly measure variables such as volume changes, surface area changes or untouched canal wall changes. The advent of micro-computer tomography, using cone-beam geometry, revolutionized how tooth studies were constructed by allowing hard and soft tissue samples to be imaged in high detail at slices as thin microns. Early studies showed that the accuracy of micro-CT scans, specifically with endodontics, was a valuable tool to test new techniques and materials (85). In 1995, Nielsen et al. published a report in our Journal of Endodontics detailing the technology's ability: The ability of the micro-CT to present accurately the external and internal morphologies of the tooth without tooth destruction; the possibility of showing changes over time in surface areas and volumes of tissues; the ability to assess area and volume changes after instrumentation or obturation; and the capability of evaluating canal transportation following instrumentation or instrumentation and obturation. (86) Since 1995, more and more studies have utilized this technology for endodontic studies. With this new imaging, previously published studies that utilized $2 \mathrm{D}$ radiographs can be re-visited to see if the results would differ compared to a micro-CT analysis. 


\section{Chapter III}

\section{Materials and methods}

\section{Specimens}

One hundred seventy human mandibular first and second molars extracted for reasons other than this study were selected from the West Virginia University School of Dentistry Research Lab Tooth Depository (IRB \#: T2017.07) (Figure 1). Teeth were further divided into first and second molars. First molar teeth were inspected under microscopic evaluation. Teeth with signs of previous endodontic treatment, cracks, micro fractures, and sings of resorption were discarded. Teeth with caries and previous restorations were included as long as the mesial roots were not affected (Figure 2).
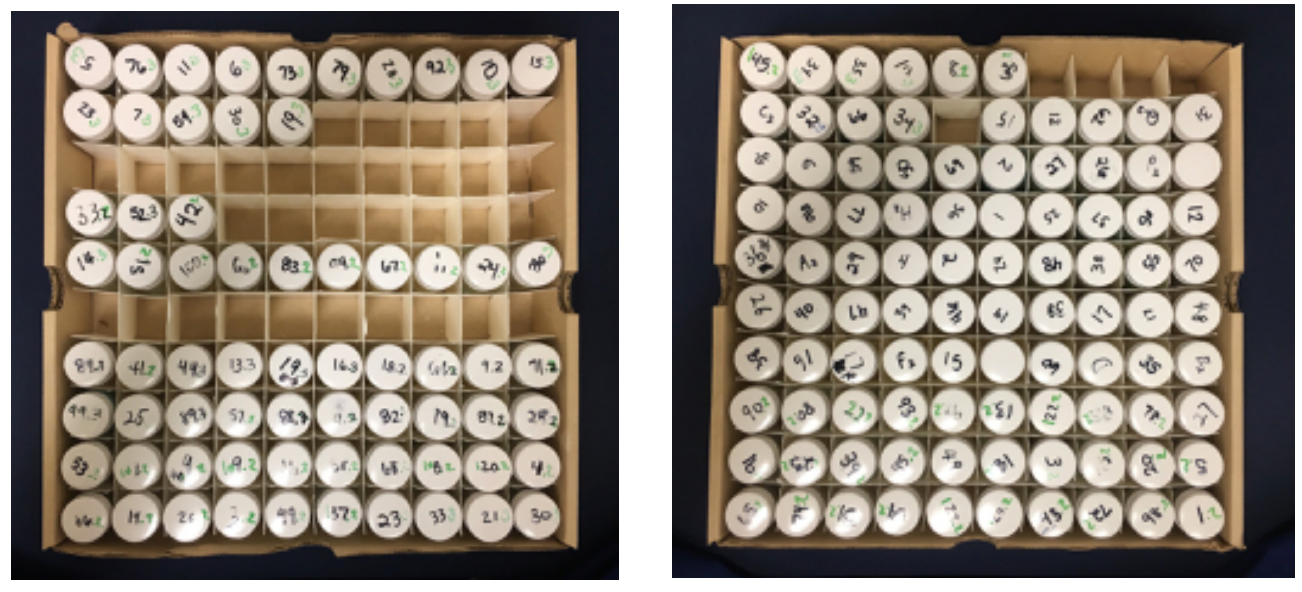

Figure 1. 170 extracted mandibular molars

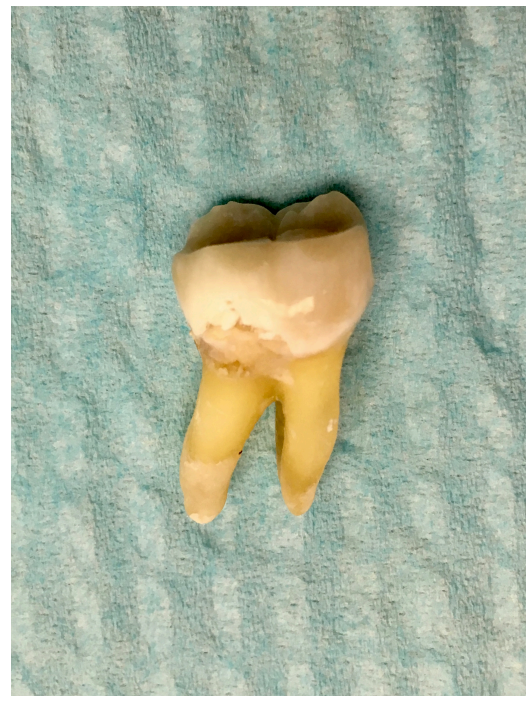

Figure 2. Example of selected tooth anatomy 
Teeth were then radiographed with digital sensors (Kodak RVG 6200; Carestream Health, Rochester, NY) in a buccal - lingual direction to evaluate the radicular canal anatomy, curvature, apical maturity and canal patency (Figure 3). The images were recorded in MiPACS imaging software (Medicor Imaging, Charlotte, NC, USA).

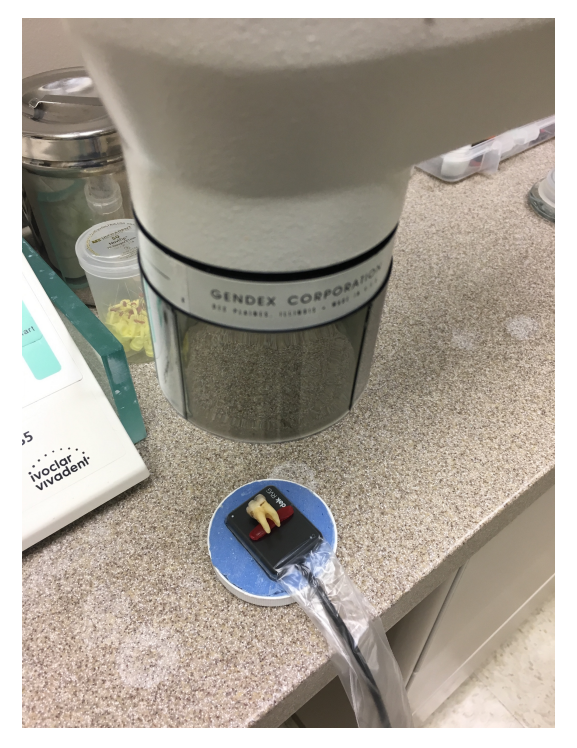

Figure 3. Radiograph for each tooth

Teeth with calcified canals, treacherous internal anatomy, and non-patent apices were discarded. Teeth with more than 40-degree canal curvature were also excluded (87). Exclusion and inclusion criteria reduced the pool of teeth to fifty-five.

The molars were then sectioned in the furcation and at the cementoenamel junction with an 856coarse tapered diamond bur (Brasseler USA, Savannah, GA, USA) in a high-speed hand piece with water coolant. The distal root and clinical crown of the teeth were maintained for any possible use for future research.
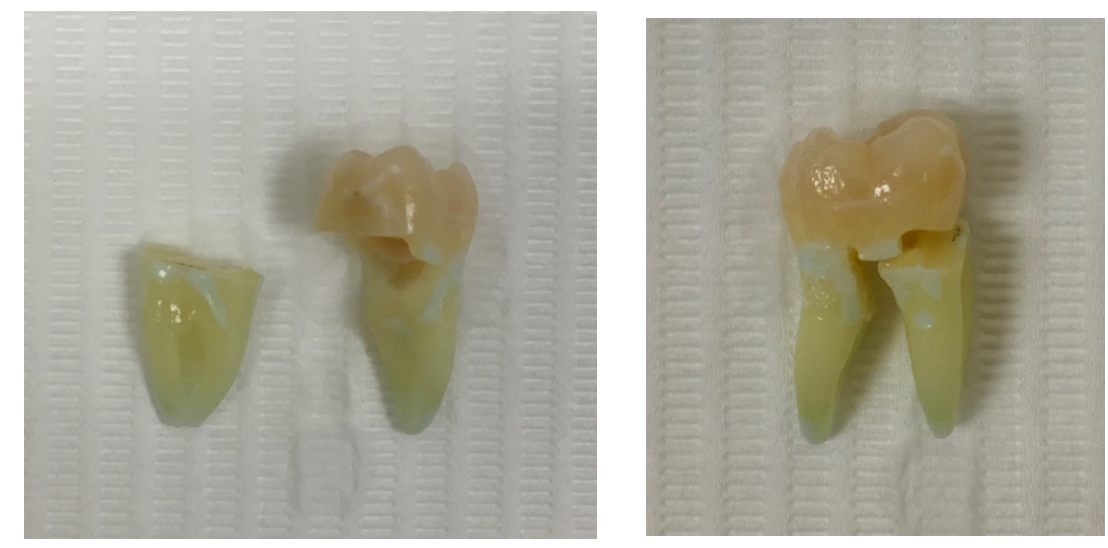

Figure 4. Sectioned mesial root and conservation of remaining tooth structure 
The mesial roots were then inspected under magnification for separate canal orifices. After visually identifying the canal orifices with an endodontic explorer, a $10 \mathrm{~K}$-file (Flexofile, Dentsply, Tulsa, OK, USA) was used to insure canal patency and to determine apical foramen anatomy. Any mesial roots that did not have canal patency with a $10 \mathrm{~K}$-file were discarded leaving forty mesial roots for the study. The roots were then divided into four equal groups of ten. Each group included the same number of mesial roots with six roots of 2 to 2 and four roots of 2 to 1 radicular canal morphology (88). Teeth were stored in sterile water throughout the study (Figure 5).

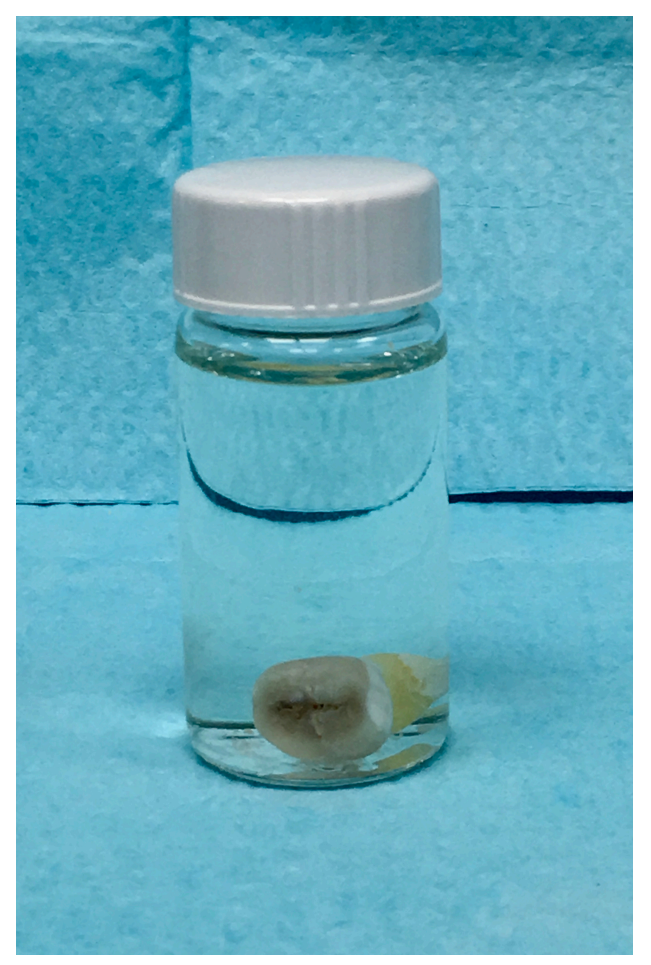

Figure 5. Tooth stored in sterile glass tubes 


\section{Root canal preparation:}

1. Working length (WL) was determined by placing a $10 \mathrm{~K}$-file into the mesial-buccal and mesiolingual root canals until the tip of the file was observed in the apical foramen. $0.5 \mathrm{~mm}$ was subtracted from the visible file tip for the effective WL of each canal.

2. After instrumenting a $10 \mathrm{~K}$-file to WL, a rotary ProGlider NiTi instrument (Dentsply, Tulsa, OK, USA) (Figure 6) was used according to manufacturer suggested method and settings (300 RPM speed / 5.0 Ncm torque) until WL was achieved with a ProMark Electric Rotary Motor (Dentsply, Tulsa, OK, USA) with an 8:1 ratio hand piece (Figures 7 and 8).

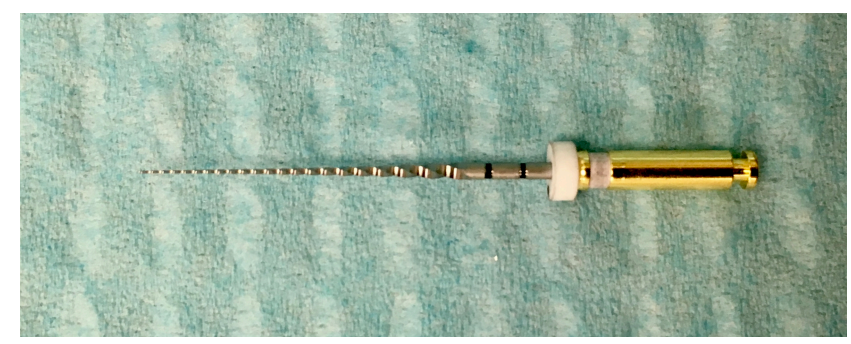

Figure 6. Dentsply ProGlider NiTi file

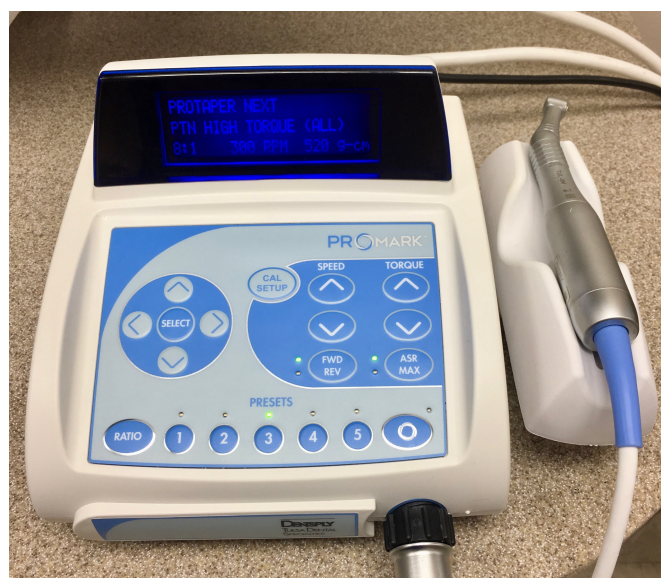

Figure 7. Dentsply ProMark Rotary Motor

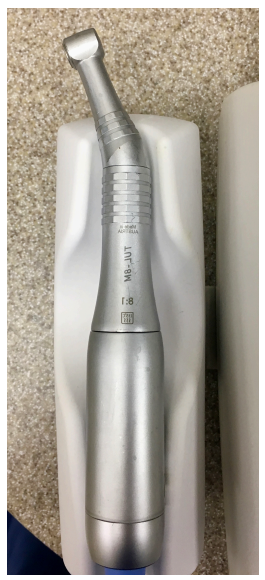

Figure 8. 8:1 Electric Hand Piece 
3. Rotary NiTi ProTaper Gold instruments (Dentsply, Tulsa, OK, USA) (Figure 9) S1 and S2 were used to resistance in alternating fashion according to their manufactured suggested settings in order to create coronal flare of the canals.

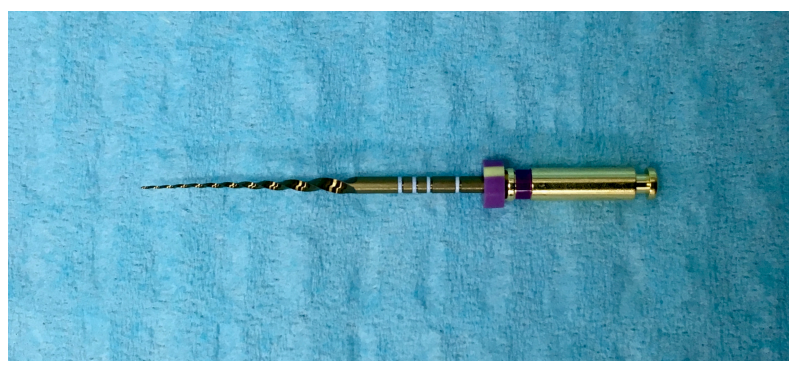

Figure 9. Dentsply ProTaper Gold S1 NiTi file

4. Vortex Blue (VB) NiTi rotary instruments (Dentsply, Tulsa, OK, USA) (Figure 10) were used to complete the apical instrumentation. The files were used according to their manufacturer settings (500 RPM / 100-200 Ncm torque) in a step-back sequence.

- All canals were prepared to a size 30, 0.06 taper at WL in the following sequence: VB size 20, 0.04 taper, VB size 25, 0.04 taper, VB size 25, 0.06 taper, VB size 30, 0.04 taper, VB size $30,0.06$ taper.

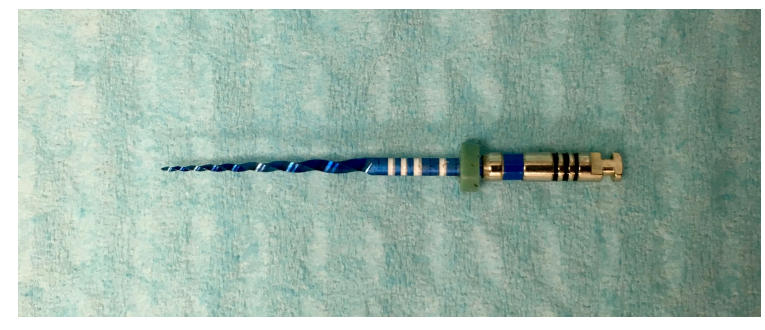

Figure 10. Dentsply Vortex Blue 30.06 NiTi file

During instrumentation, root canals were irrigated with $2 \mathrm{ml} \mathrm{NaOCl}(8.25 \%)$ between each file, delivered by a standard needle irrigation (SNI) with a 30-guage side vented needle (ProRinse, Dentsply, Tulsa, OK, USA). Recapitulation was completed with a $10 \mathrm{~K}$-file set $1.0 \mathrm{~mm}$ longer than WL between NiTi instruments.

A final irrigation protocol of $5 \mathrm{~mL}$ of $\mathrm{NaOCl}(8.25 \%)$ followed by $2 \mathrm{~mL}$ of QMix 2:1 solution (Dentsply, Tulsa, OK, USA) was implemented for each canal. Both final irrigation solutions were activated with a medium EndoActivator (Dentsply, Tulsa, OK, USA) tip for 60 seconds and dried with corresponding paper points (Figures 11 and 12). 


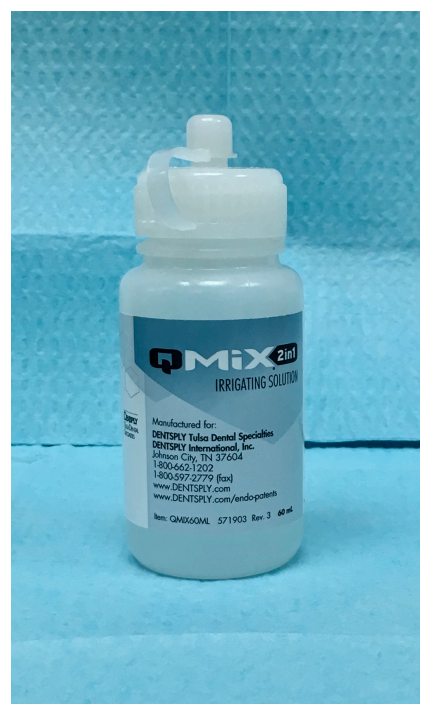

Figure 11. Dentsply QMix 2in1 Final irrigation solution

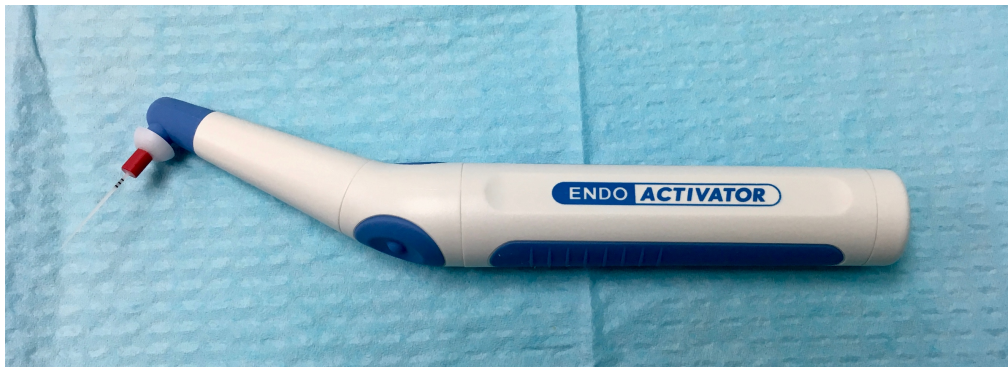

Figure 12. EndoActivator 


\section{Root canal filling (obturation):}

1. Two groups of twenty roots each were divided for obturation purposes. Twenty roots were filled with Brasseler EndoSequence (Brasseler USA) machine matched size and taper gutta percha and twenty roots were fitted with Brasseler EndoSequence Bioceramic machine match size and taper gutta percha (Figures 13 and 14). All roots, independent of the specific type of gutta percha used, were cemented with a bioceramic sealer, BC Sealer (Brasseler USA) (Figure 15).

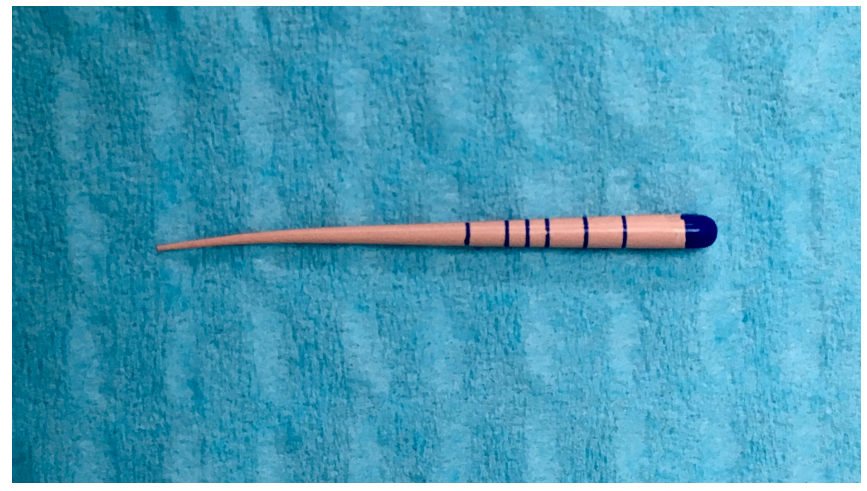

Figure 13. Brasseler EndoSequence Gutta Percha Points (TGP)

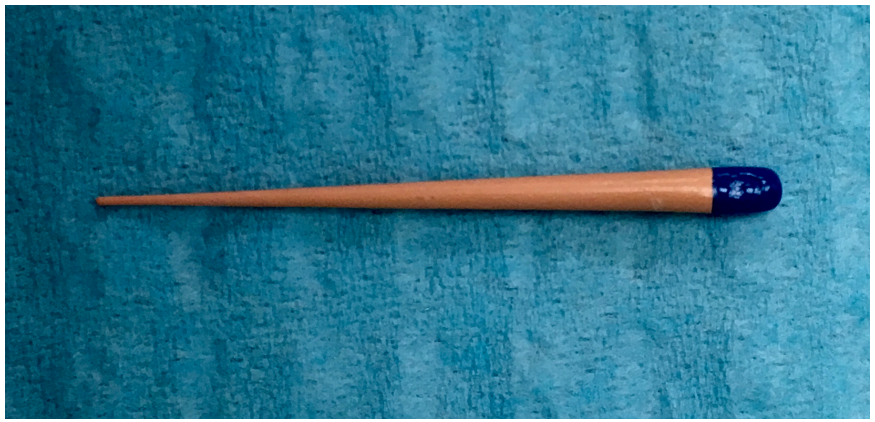

Figure 14. Brasseler EndoSequence BC Points (BC)

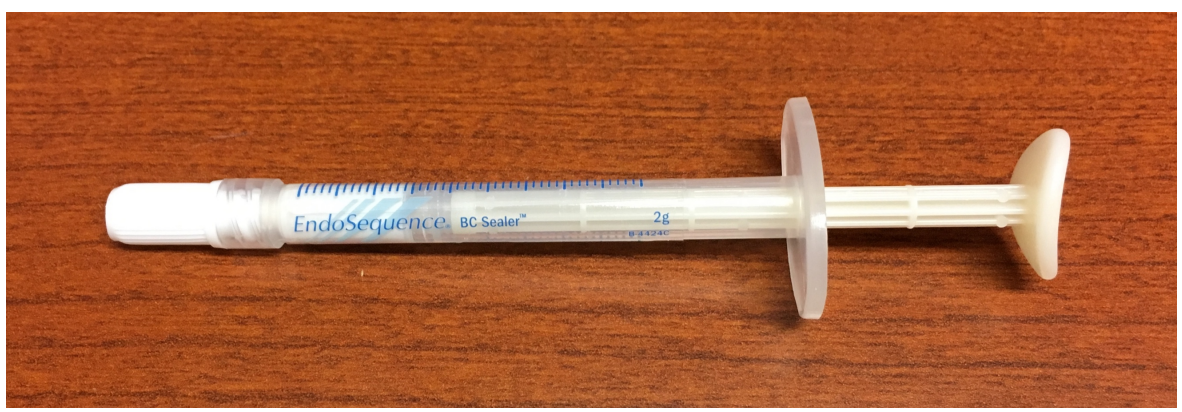

Figure 15. Brasseler EndoSequence BC Sealer 
2. A corresponding size 30, 0.06 taper gutta percha cone was fit into each canal with tug back at WL.

3. The canals were then filled with BC Sealer according to the manufactured recommended technique.

4. The single cone, 30.06 gutta percha, was then slowly seated to WL and seared off at the orifice with an Elements Free (Kerr Endo) and lightly compacted with a plunger according to the single cone technique promoted for BC Sealer obturation.

5. Extruded sealer was wiped off the apical areas with a damp 2 x 2 gauze.

Teeth were stored at 37 degrees in 100 percent humidity for 14 days to allow complete set of the sealer. Humidity was maintained by wrapping the root in a damp $2 \times 2$ gauze and placing two damp cotton rolls in a zip lock bag. (Figures 16, 17, and 18).

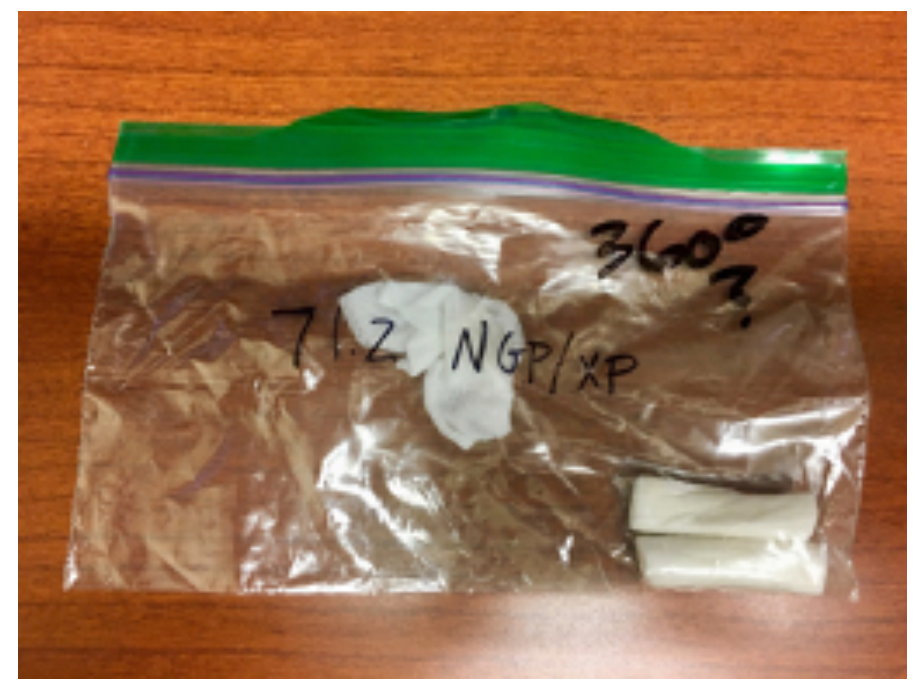

Figure 16. Wrapped mesial root and damp cotton rolls 

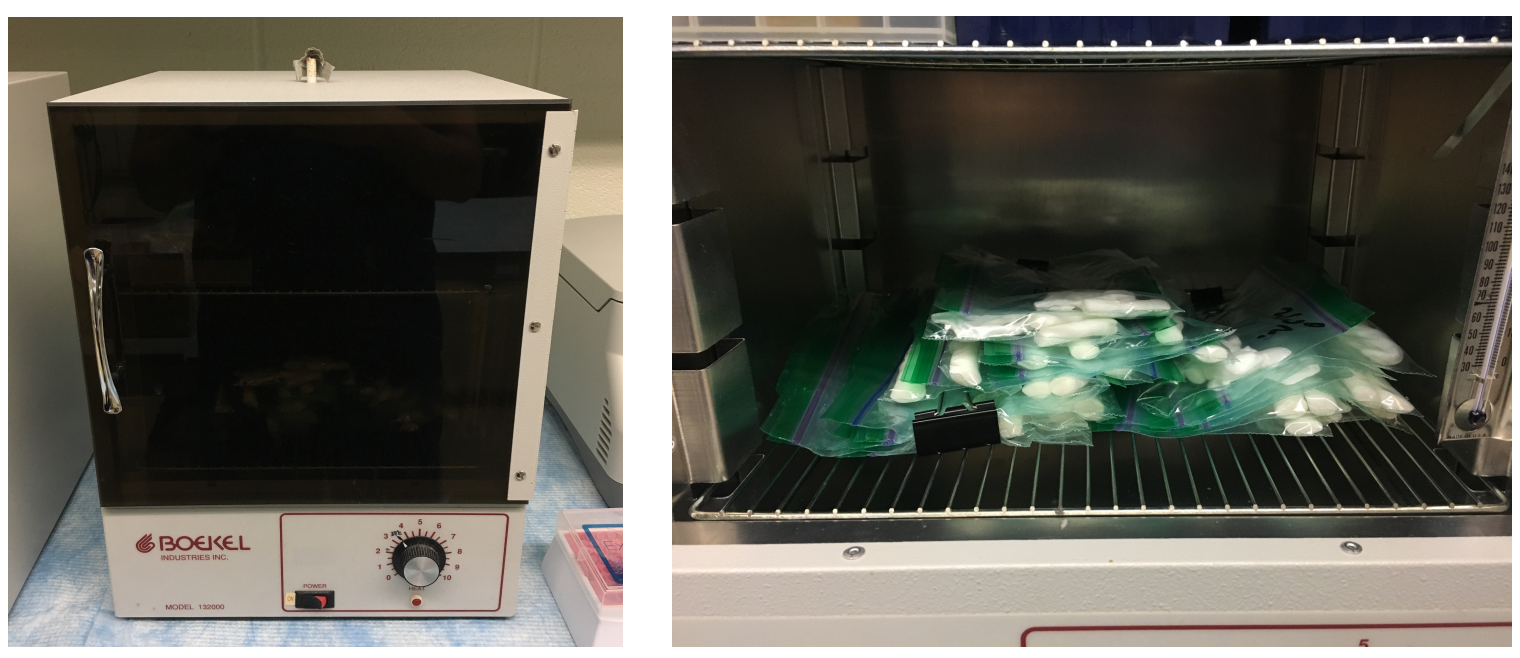

Figure 17. Boekel oven

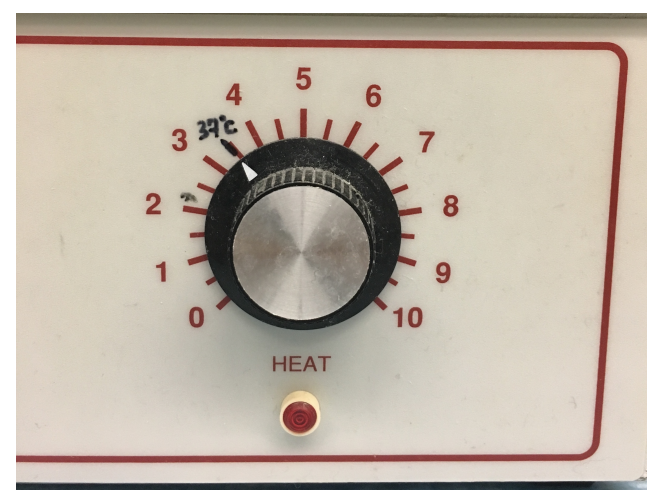

Figure 18. Temperate at 37 degrees Celsius 


\section{Retreatment:}

The retreatment procedure was completed by removing the previously filled canals with one of the following instruments: TRUShape NiTi (TS) (Dentsply, Tulsa, OK, USA) (Figure 19) or XP Shaper NiTi (XP) (Brasseler USA, Savannah, GA, USA) (Figure 20).

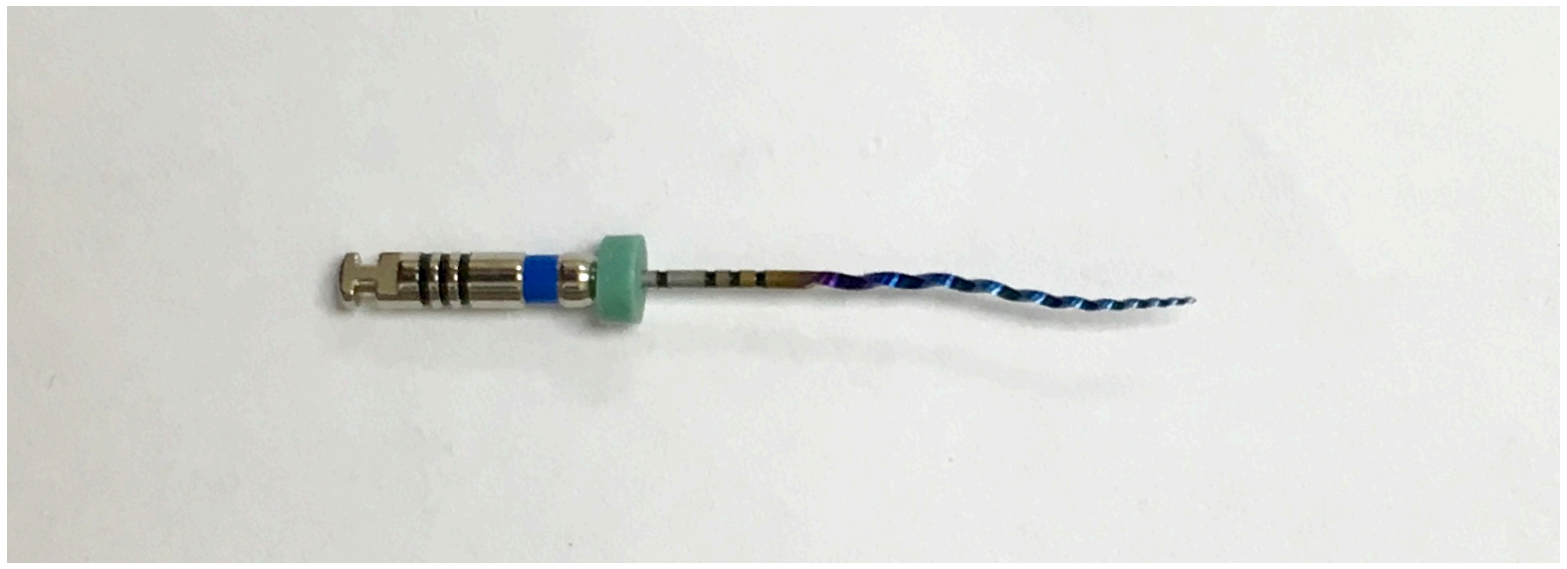

Figure 19. Dentsply TRUShape 30.06 NiTi file

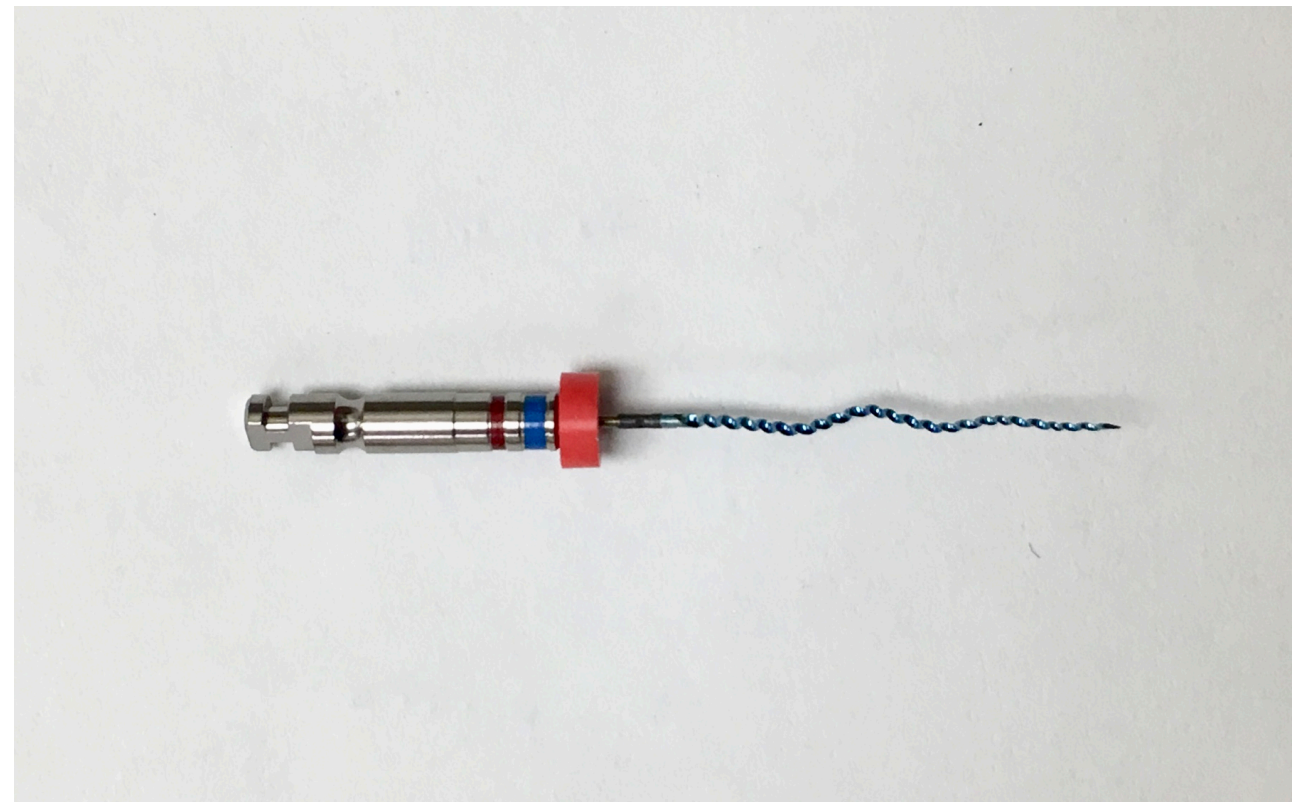

Figure 20. Brasseler XP Shaper NiTi file 
As mentioned previously, four groups were divided based upon an even number of canal morphologies into sample sizes of ten:

\section{Group 1: Traditional Gutta Percha / TRUShape (TGP/TS) \\ Group 2: Bioceramic Gutta Percha / TRUShape (BC/TS) \\ Group 3: Traditional Gutta Percha / XP Shaper (TGP/XP) \\ Group 4: Bioceramic Gutta Percha / XP Shaper (BC/XP)}

\section{Groups $1(T G P / T S)$ and $2(B C / T S)$ :}

A crown down method was used with TS instruments. Size 40, 0.06 taper, size 30, 0.06 taper, size 25, 0.06 taper were used until the previously established working length was reached and the file flutes were void of any obturation debris. The size 30, 0.06 taper file was used in canals if WL and canal patency was regained. A speed of 900 RPM and a torque of $3.0 \mathrm{Ncm}$ was used for each file size with a ProMark (Dentsply, Tulsa, OK, USA) electronic motor and 8:1 ratio hand piece. The files were advanced in $3 \mathrm{~mm}$ amplitudes with a brushing motion. After three in-and-out brushing strokes, the file was removed and cleaned. $2 \mathrm{ml}$ of $\mathrm{NaOCl}(8.25 \%)$ was used to irrigate between each file during the retreatment procedure. A new file was used in each mesial root and then discarded. A final irrigation protocol of $5 \mathrm{ml} \mathrm{NaOCl}$ (8.25\%) and $5 \mathrm{ml}$ EDTA (17\%) were used along with paper points to remove excess moisture. The teeth were then placed back in $100 \%$ humidity.

Groups $3(T G P / X P)$ and $4(B C / X P)$ :

The XP Shaper (XP) was used according to the manufacturer's recommendations of 1,000 RPM / $1 \mathrm{Ncm}$. The WL was set $0.5 \mathrm{~mm}$ shorter than the original WL per the file's DFU. Long gentle strokes of 5-7 mm were used to progress to the apex. If WL was not reached in 5 strokes, the file was removed and cleaned and reinserted into the canal. Once the WL was reached, the file was cleaned and re-inserted for another 10 seconds. $2 \mathrm{ml}$ of $\mathrm{NaOCl}(8.25 \%)$ was used to irrigate between filing during the retreatment procedure. New instruments were used in each mesial root and then discarded. A final irrigation protocol of $5 \mathrm{ml} \mathrm{NaOCl}(8.25 \%)$ and $5 \mathrm{ml}$ EDTA (17\%) were used along with paper points to remove excess moisture. The teeth were then placed back in $100 \%$ humidity.

\section{Termination of file use and time:}

The files were no longer considered effective when there was no filling material debris on their respective file flutes or when the file would no longer advance apically. There was no time variable in place, as we spent as long as needed in the attempt to reach the WL and achieve canal patency. 


\section{Canal Patency:}

The ability of canal patency to be regained was determined by the ability to slide a $10 \mathrm{~K}$-file through both canal foramen in $2-2$ configured roots and in one common canal foramina in $2-1$ configured roots (Figures 21 and 22). A log of the canal patency was kept for each sample number.

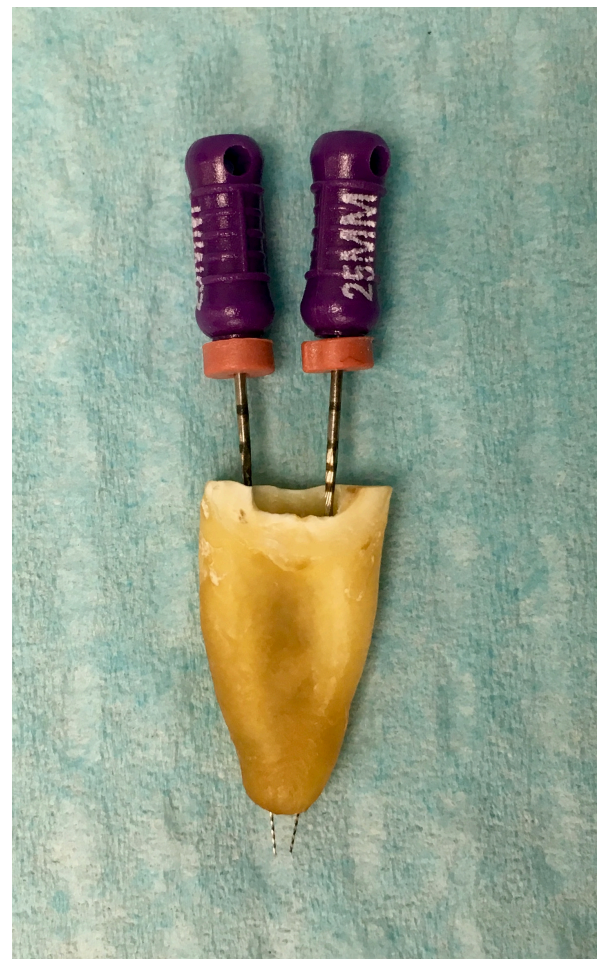

Figure 21. $10 \mathrm{~K}$-files through canal foramen

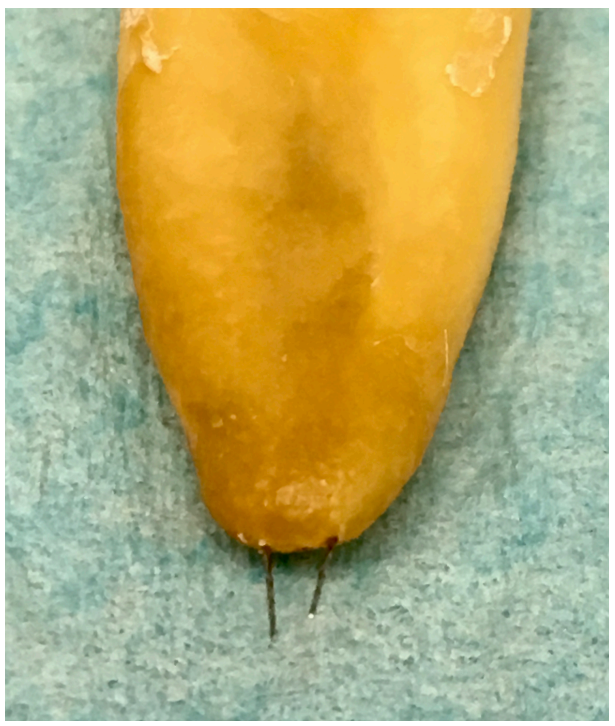

Figure 22. Close up of hand files illustrating canal patency 


\section{Micro-CT imaging analysis*}

The samples were scanned by a micro-CT device (AMIF SkyScan 1272 v1.1.10; Bruker micro$\mathrm{CT}$, Kontich, Belgium) at two time points (fourteen days post-obturation and after retreatment) with the following parameters: $100 \mathrm{kV}, 18$ um magnification, 1344 x 896 binning, 18 um pixel resolution with a $1.0 \mathrm{~mm}$ think copper filter. A 180 -degree scan was used with a 0.4 rotation step with an average of 2 frames. A flat field correction of 1753 was used for all scans. The twodimensional images were cropped with the Dataviewer software v 1.5.3.4 64 Bit (Bruker micro$\mathrm{CT})$. The acquired images were reconstructed into cross-sectional slices using NRecon v1.7.1.0 (Bruker micro-CT). The volume of interest was selected to extend from the cemento-enamel junction to the apex of the root, resulting in the acquisition of 700-800 transverse cross sections per root. The residual filling material volume $\left(\mathrm{mm}^{3}\right)$ and surface area $\left(\mathrm{mm}^{2}\right)$ was quantified for all the root canals using CTAn v 1.16.9.0 64 bit software (Bruker micro-CT) after obturation and after retreatment. Quantitative three-dimensional evaluation of the remaining filling surface and volume was obtained using the plugin three-dimensional analysis tool in the CTvol software v 2.3.2.0 64 Bit (Bruker micro-CT).

*Figures 23-30: Micro-CT hardware and resulting images. / Tables 1-4: Raw data generated within CTAn software

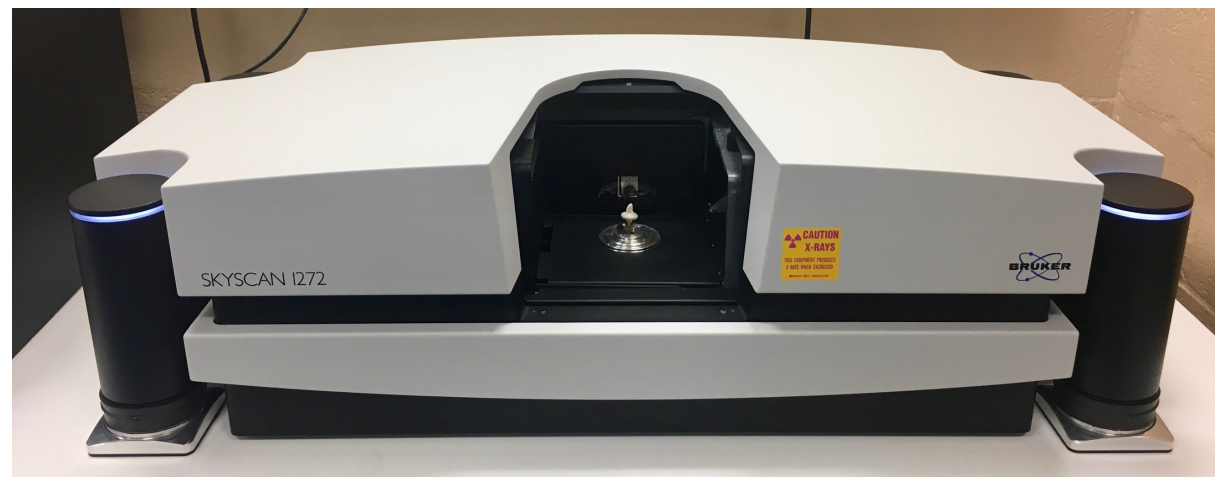

Figure 23. Bruker SkyScan 1272

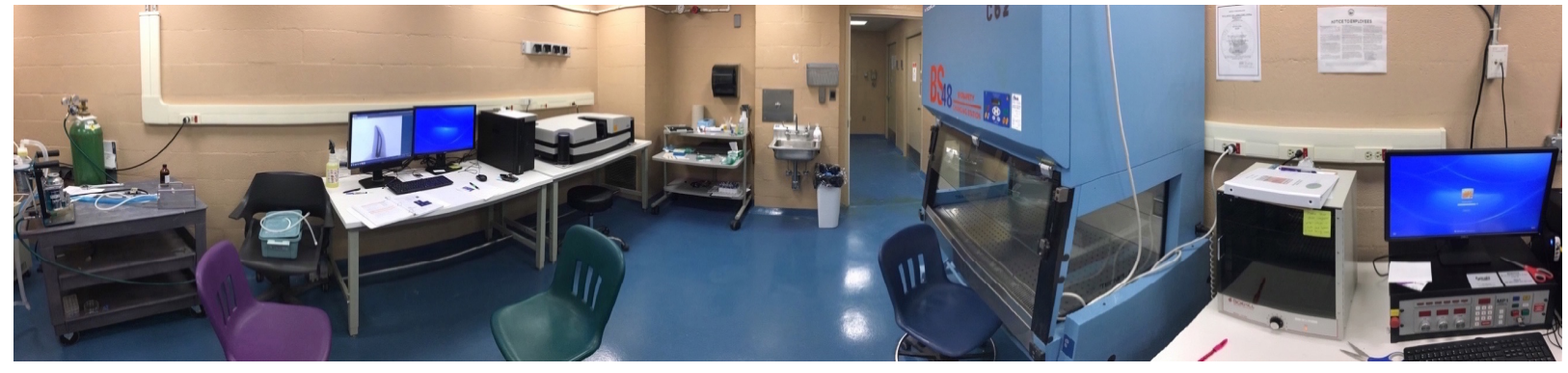

Figure 24. Animal Research Facility 


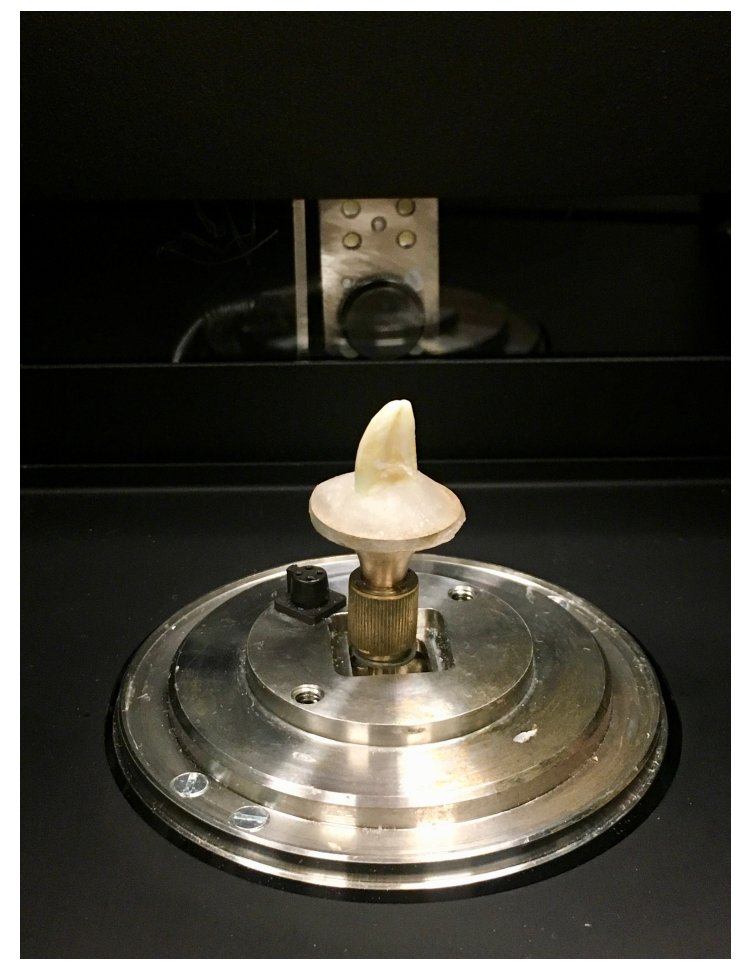

Figure 25. Mesial root on micro-CT crucible

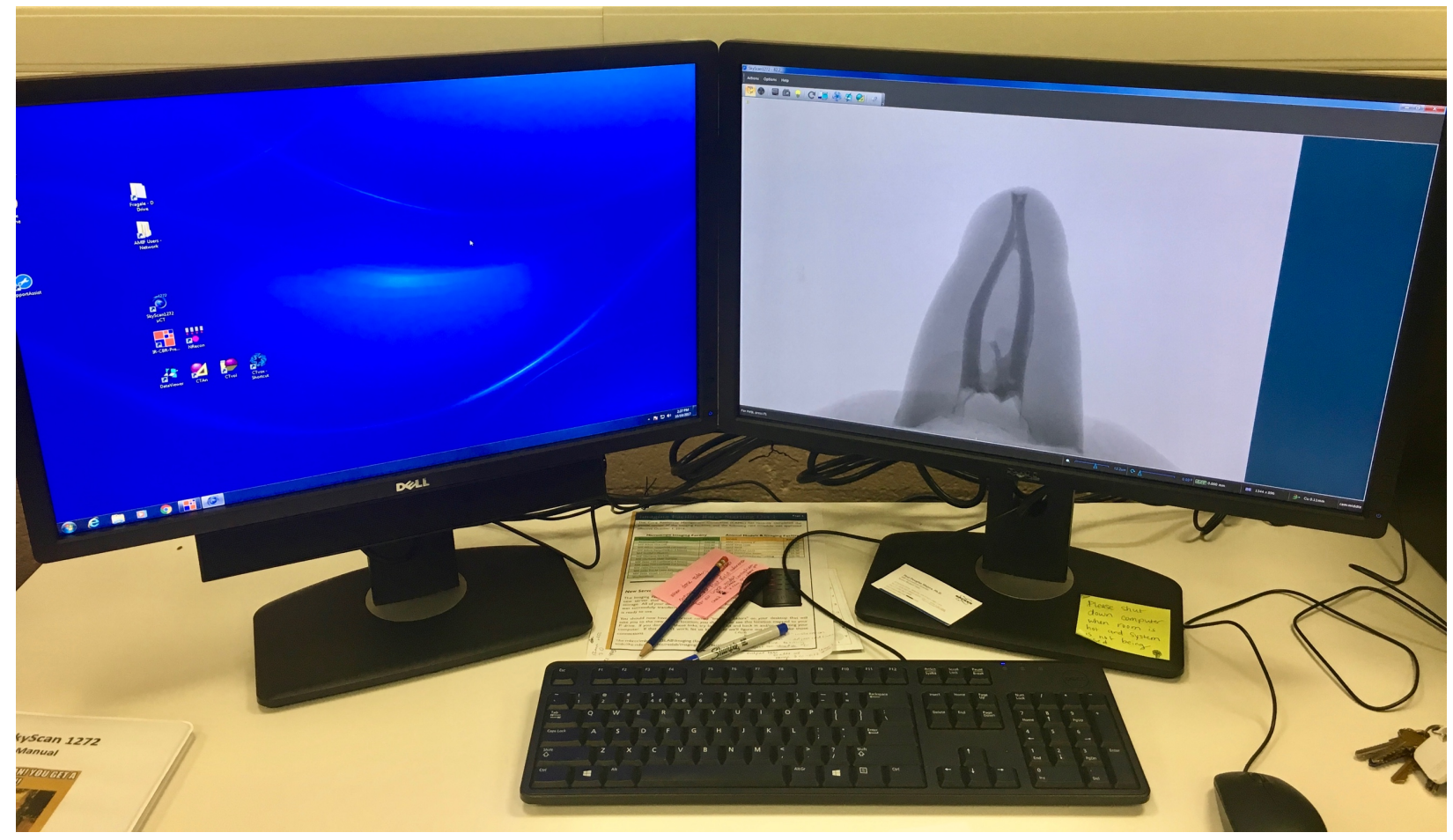

Figure 26. Software station for data analysis 

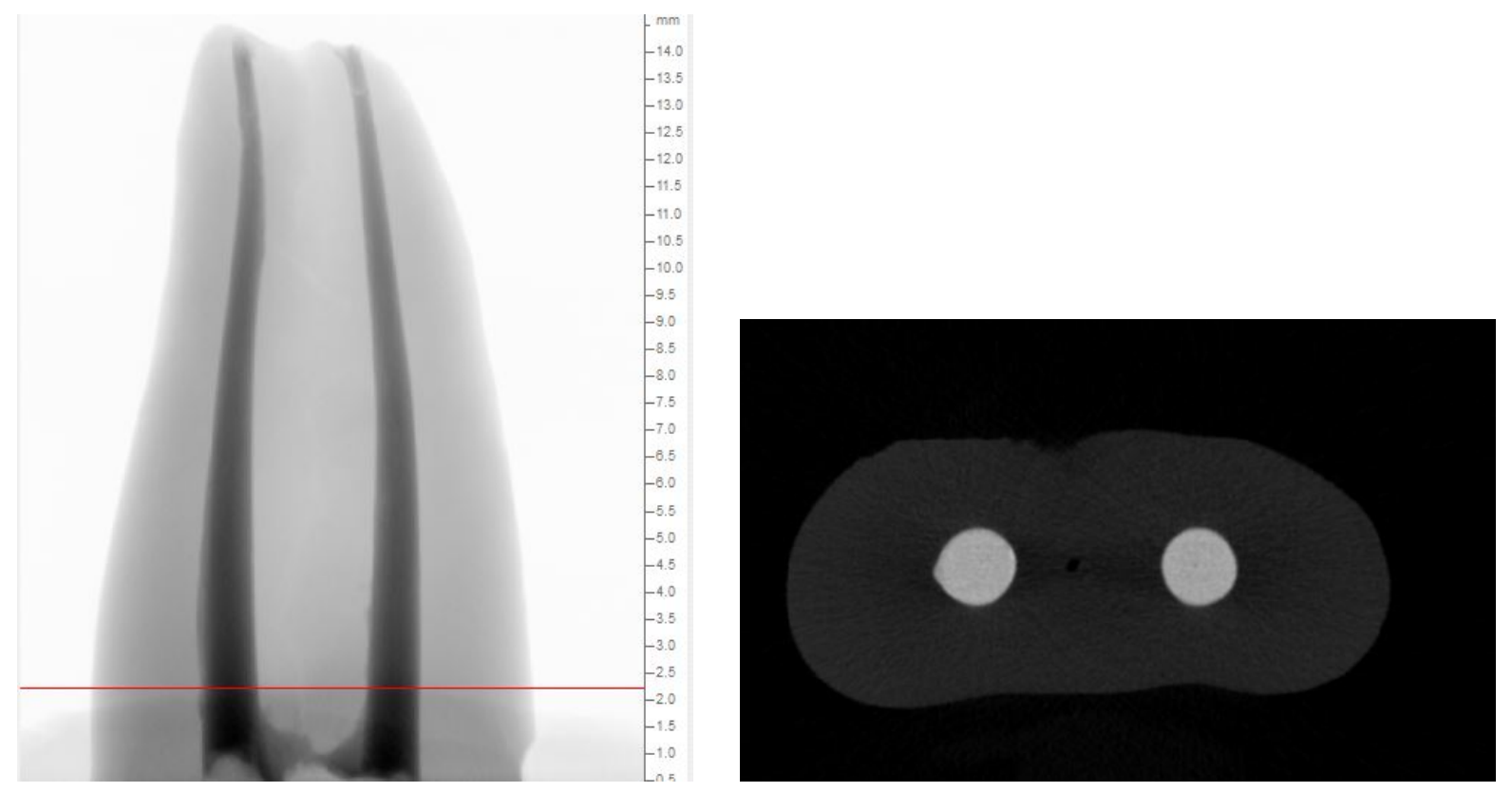

Figure 27. Example of a micro-CT image and slice of obturated root from DataViewer software
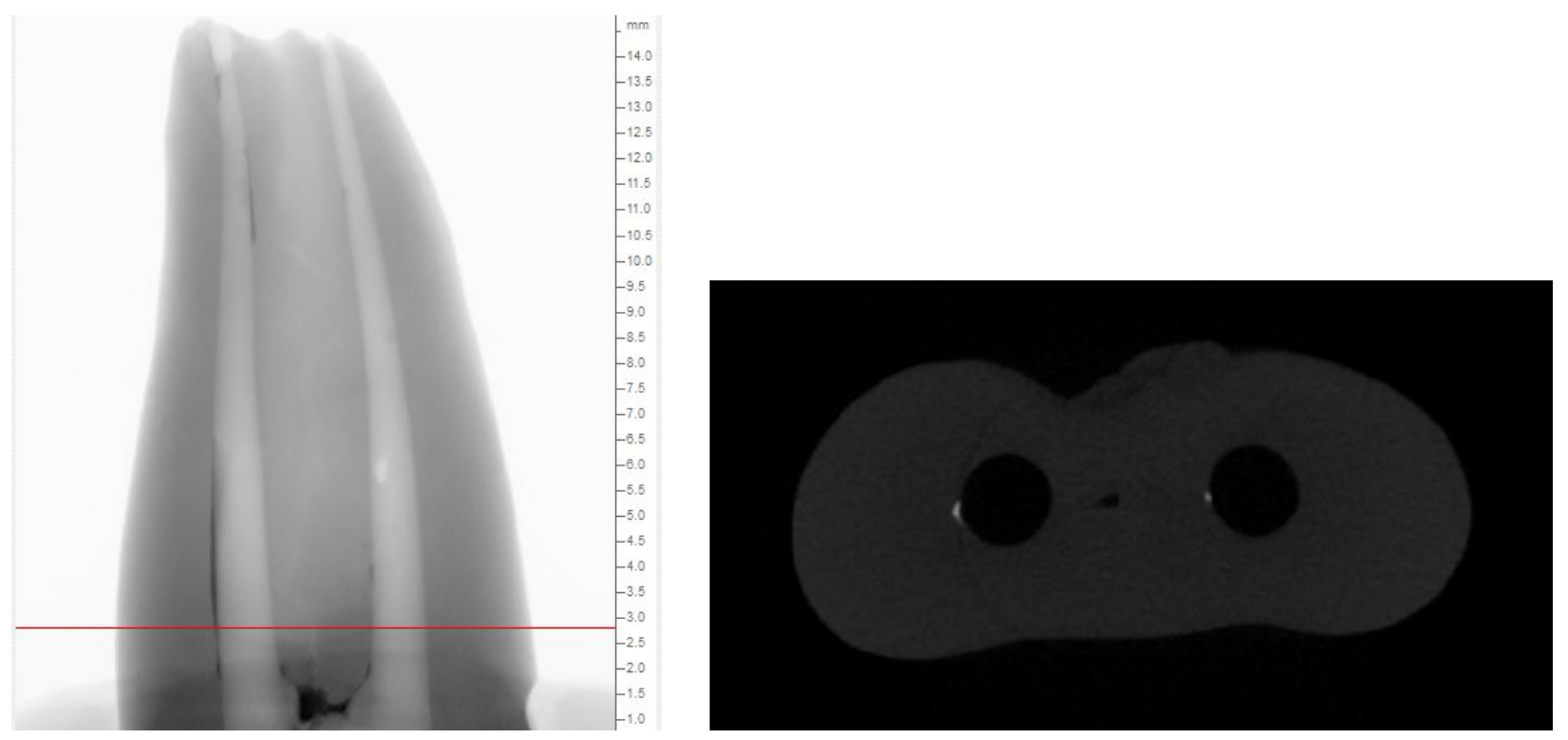

Figure 28. Example of micro-CT image and slice of retreated root from DataViewer software 


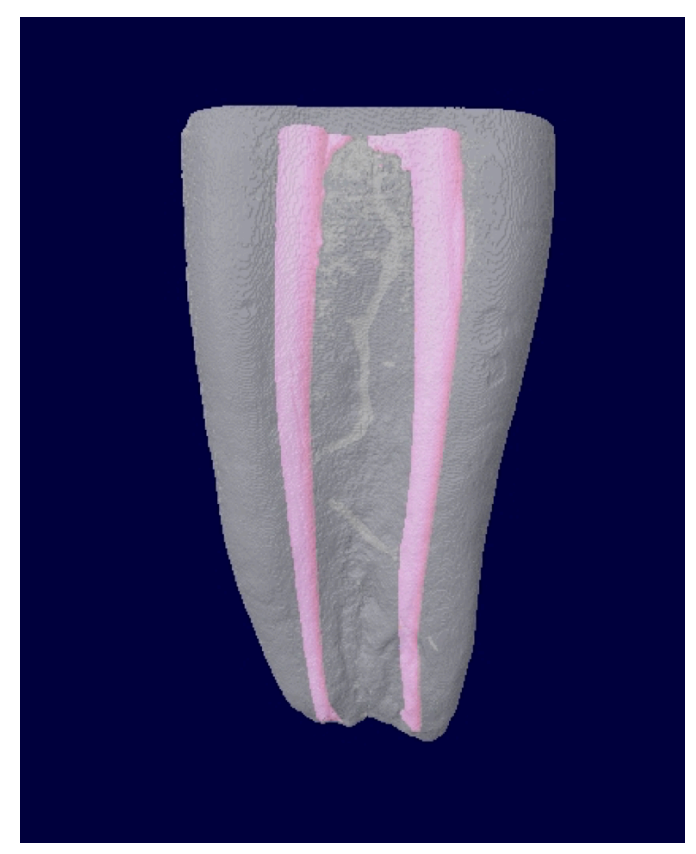

Figure 29. Example of 3D reconstruction of obturated root by CTvol software

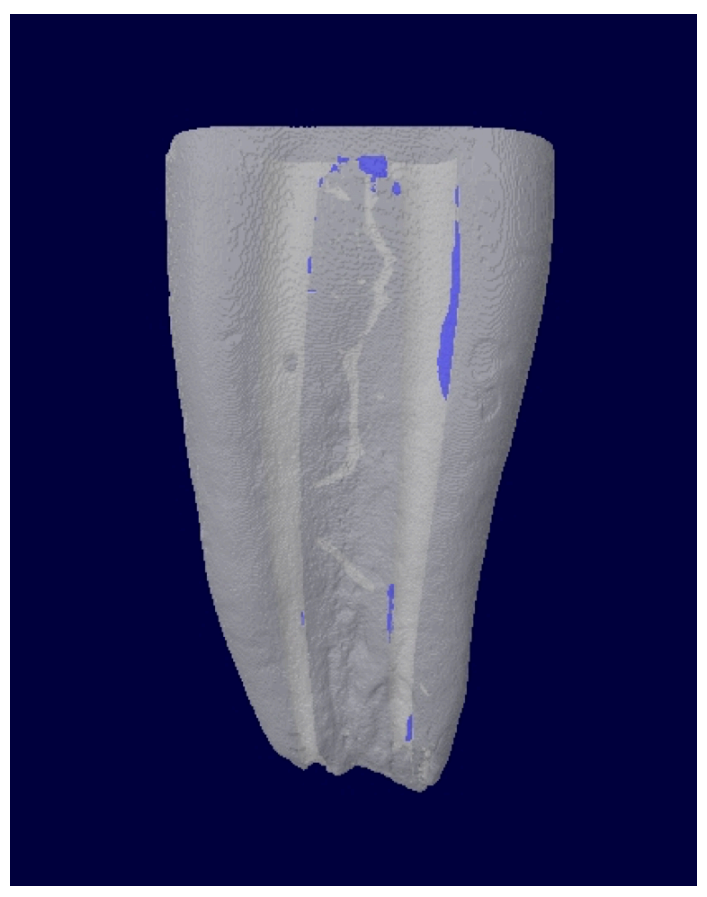

Figure 30. Example of 3D reconstruction of retreated root by CTvol software 


\begin{tabular}{|c|c|c|c|}
\hline Description & Atbreviation & Value & Unit: \\
\hline Total VOI volume & TV & 1294.26721 & $\mathrm{~mm}^{\wedge} 3$ \\
\hline Dbject volume & Dbj.y & 11.34072 & $\mathrm{~mm}^{\wedge} 3$ \\
\hline Percent object volume & Dbi.W/TV & 0.87623 & $\%$ \\
\hline Total VOI surface & TS & 716.21075 & $\mathrm{~mm}^{\wedge} 2$ \\
\hline Dbject surface & Dbj.s & 65.95315 & $\mathrm{~mm}^{2} 2$ \\
\hline Intersection surface & i.s & 2.29105 & $\mathrm{~mm}^{\wedge} 2$ \\
\hline Dbject surface / volume ratio & obi.s/0bi. & 5.81560 & $1 / \mathrm{mm}$ \\
\hline Object surface density & Dbj.s/TV & 0.05096 & $1 / \mathrm{mm}$ \\
\hline Surface convexity index & SCv.I & 2.89719 & $1 / \mathrm{mm}$ \\
\hline Centroid $[x]$ & $\operatorname{Crd} X$ & 5.39476 & $\mathrm{~mm}$ \\
\hline Centroid $[y]$ & Crd.Y & 5.30307 & $\mathrm{~mm}$ \\
\hline Centroid [z] & $\operatorname{Crd} Z$ & 6.22628 & $\mathrm{~mm}$ \\
\hline
\end{tabular}

Table 1. Data generated by CTAn software of obturated root (object volume and object surface)

\begin{tabular}{|c|c|c|c|}
\hline Description & Abbreviation & Value & Unit \\
\hline Total V0I volume & $\mathrm{TV}$ & 879.72716 & $\mathrm{~mm}^{\wedge} 3$ \\
\hline Dbject volume & abi. V & 3.13818 & $\mathrm{~mm}^{3} 3$ \\
\hline Percent object volume & Dbi.W/TV & 0.35672 & $\%$ \\
\hline Total VOI surface & TS & 573.99199 & $\mathrm{~mm}^{2} 2$ \\
\hline Dbject surface & Dbi.s & 35.44994 & $\mathrm{~mm}^{2} 2$ \\
\hline Intersection surface & i.s & 0.15455 & $\mathrm{~mm}^{2} 2$ \\
\hline Dbject surface / volume ratio & Dbi.5/0bi. & 11.29633 & $1 / \mathrm{mm}$ \\
\hline Dbject surface density & Dbi.5/TV & 0.04030 & $1 / \mathrm{mm}$ \\
\hline Surface convexity index & SCv.I & 4.48329 & $1 / \mathrm{mm}$ \\
\hline Centroid $[x]$ & $\operatorname{Crd} x$ & 4.79856 & $\mathrm{~mm}$ \\
\hline Centroid [u] & Crd. $Y$ & 3.10219 & $\mathrm{~mm}$ \\
\hline Centroid [z] & $\operatorname{Crd} 2 \mathrm{Z}$ & 9.24061 & $\mathrm{~mm}$ \\
\hline
\end{tabular}

Table 2. Date generated by CTAn software of retreated root (object volume and object surface) 


\begin{tabular}{|c|c|c|c|c|c|}
\hline Specimen & File & Obturated Volume (mm3) & Obturated SA (mm2) & Retreated Volume (mm3) & Retreated SA (mm2) \\
\hline $4.2 \mathrm{BC}$ & $\mathrm{XP}$ & 10.95319 & 62.55546 & 1.41327 & 16.1625 \\
\hline $53.2 \mathrm{BC}$ & $\mathrm{XP}$ & 6.92455 & 47.30627 & 3.83964 & 41.73377 \\
\hline $58.2 \mathrm{BC}$ & $\mathrm{XP}$ & 6.71715 & 46.66465 & 1.32846 & 21.4982 \\
\hline $68.2 \mathrm{BC}$ & $\mathrm{XP}$ & 11.87753 & 67.40994 & 5.48726 & 60.28479 \\
\hline $107.2 \mathrm{BC}$ & $\mathrm{XP}$ & 11.17211 & 65.77104 & 3.67028 & 43.29834 \\
\hline $108.2 \mathrm{BC}$ & $\mathrm{XP}$ & 10.84371 & 55.03814 & 6.41927 & 47.56729 \\
\hline $109.2 \mathrm{BC}$ & $\mathrm{XP}$ & 8.14012 & 52.77503 & 0.84914 & 16.52538 \\
\hline $120.2 \mathrm{BC}$ & XP & 8.09667 & 51.9884 & 2.64128 & 35.9002 \\
\hline $409.2 \mathrm{BC}$ & $\mathrm{XP}$ & 5.67273 & 39.05094 & 2.28674 & 22.41624 \\
\hline M2.2 BC & $\mathrm{XP}$ & 6.26853 & 43.4033 & 1.8869 & 26.11354 \\
\hline $3.2 \mathrm{BC}$ & Tru & 6.52314 & 45.7966 & 0.27858 & 8.43229 \\
\hline 14.2 BC & Tru & 10.57421 & 64.84623 & 0.46085 & 11.50008 \\
\hline $21.3 \mathrm{BC}$ & Tru & 7.23661 & 47.05921 & 1.64646 & 19.55458 \\
\hline $23.3 \mathrm{BC}$ & Tru & 8.54412 & 53.47922 & 1.1385 & 20.84635 \\
\hline $26.2 \mathrm{BC}$ & Tru & 10.08894 & 62.13493 & 1.01459 & 19.68384 \\
\hline $30.3 \mathrm{BC}$ & Tru & 8.67473 & 54.07577 & 0.28865 & 12.55607 \\
\hline $33.3 \mathrm{BC}$ & Tru & 7.79054 & 48.70993 & 1.55852 & 31.84906 \\
\hline $49.2 \mathrm{BC}$ & Tru & 8.23511 & 53.97429 & 1.5972 & 37.34993 \\
\hline $86.2 \mathrm{BC}$ & Tru & 11.37213 & 67.7981 & 0.06488 & 3.60814 \\
\hline $137.2 \mathrm{BC}$ & Tru & 6.07181 & 44.73695 & 0.63147 & 12.82813 \\
\hline 9.2 Traditional & XP & 4.22412 & 33.42727 & 0.97711 & 16.03213 \\
\hline 13.3 Traditional & XP & 6.96208 & 51.66246 & 0.51683 & 12.26332 \\
\hline 16.3 Traditional & XP & 6.37252 & 47.27476 & 0.19568 & 7.4222 \\
\hline 18.2 Traditional & XP & 8.32607 & 55.509 & 0.90404 & 13.67632 \\
\hline 19.3 Traditional & XP & 6.90857 & 47.81493 & 0.69485 & 14.71294 \\
\hline 41.2 Traditional & XP & 6.43232 & 43.14716 & 1.1172 & 16.71847 \\
\hline 44.3 Traditional & XP & 7.58062 & 55.89813 & 0.85293 & 18.67312 \\
\hline 61.2 Traditional & XP & 5.16613 & 37.67374 & 0.10285 & 3.7501 \\
\hline 71.2 Traditional & XP & 7.48004 & 49.23635 & 1.10517 & 17.84231 \\
\hline 84.3 Traditional & XP & 15.84664 & 101.75157 & 3.83335 & 48.00869 \\
\hline 21.2 Traditional & Tru & 10.48785 & 62.11129 & 0.14305 & 5.08733 \\
\hline 25.3 Traditional & Tru & 11.01935 & 65.29658 & 0.30769 & 10.00321 \\
\hline 28.2 Traditional & Tru & 6.61847 & 45.27054 & 0.07227 & 3.21688 \\
\hline 57.2 Traditional & Tru & 6.55183 & 43.27037 & 0.3746 & 10.04546 \\
\hline 82.2 Traditional & Tru & 6.82342 & 47.8536 & 0.56075 & 15.84289 \\
\hline 87.2 Traditional & Tru & 9.53064 & 58.07074 & 0.16351 & 5.70954 \\
\hline 88.2 Traditional & Tru & 9.87156 & 60.53663 & 0.09008 & 4.0061 \\
\hline 89.3 Traditional & Tru & 7.448 & 47.6431 & 0.14058 & 6.02131 \\
\hline 99.2 Traditional & Tru & 8.18565 & 58.58346 & 0.59825 & 20.50296 \\
\hline 99.3 Traditional & Tru & 12.52344 & 70.86334 & 0.35909 & 9.0306 \\
\hline
\end{tabular}

Table 3. Raw data for obturated and retreated specimens as object volume and object surface from CTAn software

\begin{tabular}{|c|c|c|c|c|}
\hline Group & Sample \# & GP & File & Patency \\
\hline 1 & $4.2 \mathrm{E}$ & & $X P$ & $\mathrm{~N}$ \\
\hline 1 & $53.2 \mathrm{E}$ & & XP & $\mathrm{N}$ \\
\hline 1 & $58.2 \mathrm{E}$ & & XP & $\mathrm{N}$ \\
\hline 1 & $68.2 \mathrm{E}$ & & XP & $\mathrm{N}$ \\
\hline 1 & $107.2 \mathrm{E}$ & & XP & $\mathrm{N}$ \\
\hline 1 & 108.2 & & XP & N \\
\hline 1 & $109.2 \mathrm{E}$ & & XP & Y \\
\hline 1 & $120.2 \mathrm{E}$ & & XP & $\mathrm{N}$ \\
\hline 1 & $409.2 \mathrm{E}$ & & XP & $\mathrm{N}$ \\
\hline 1 & M2.2 & & XP & $\mathrm{N}$ \\
\hline 2 & 3.2 & & Tru & $\mathrm{N}$ \\
\hline 2 & 14.2 & & Tru & Y \\
\hline 2 & 21.3 & & Tru & $\mathrm{N}$ \\
\hline 2 & 23.3 & & Tru & $\mathrm{N}$ \\
\hline 2 & 26.2 & & Tru & $\mathrm{N}$ \\
\hline 2 & 30.3 & & Tru & y \\
\hline 2 & 33.3 & & Tru & $\mathrm{N}$ \\
\hline 2 & 49.2 & & Tru & Y \\
\hline 2 & 86.2 & & Tru & y \\
\hline 2 & 137.2 & & Tru & $\mathrm{N}$ \\
\hline 3 & 9.2 & raditional & XP & $\mathrm{N}$ \\
\hline 3 & 13.3 & raditional & XP & y \\
\hline 3 & 16.3 & raditional & XP & Y \\
\hline 3 & 18.2 & raditional & XP & $\mathrm{N}$ \\
\hline 3 & 19.3 & raditional & XP & $\mathrm{N}$ \\
\hline 3 & 41.2 & raditional & XP & Y \\
\hline 3 & 44.3 & raditional & XP & $\mathrm{N}$ \\
\hline 3 & 61.2 & raditional & XP & y \\
\hline 3 & 71.2 & raditional & XP & $\mathrm{N}$ \\
\hline 3 & 84.3 & raditional & XP & y \\
\hline 4 & 21.2 & raditional & Tru & Y \\
\hline 4 & 25.3 & raditional & Tru & Y \\
\hline 4 & 28.2 & raditional & Tru & Y \\
\hline 4 & 57.2 & raditional & Tru & $\mathrm{N}$ \\
\hline 4 & 82.2 & raditional & Tru & Y \\
\hline 4 & 87.2 & raditional & Tru & Y \\
\hline 4 & 88.2 & raditional & Tru & Y \\
\hline 4 & 89.3 & Fraditional & Tru & y \\
\hline 4 & 99.2 & raditional & Tru & y \\
\hline 4 & 99.3 & raditional & Tru & $\mathrm{N}$ \\
\hline
\end{tabular}

Table 4. Number of canals patent 


\section{Statistical analysis}

SAS software was used for statistical analyses with the significance level set at $(p \leq 0.05)$. The Kruskal Wallis test was performed to evaluate significant differences in mean percentage of remaining volume and surface area among the four groups studied. If a significant difference was found, the Mann Whitney U test with the Bonferroni adjustment was performed to identify which groups significantly differed.

We were also interested in comparing whether there is a significant difference in percentage of remaining volume and surface area between $\mathrm{BC}$ gutta percha and traditional gutta percha as well as possible differences between the XP Shaper and TRUShape files. For these analyses, Mann Whitney $\mathrm{U}$ tests were performed $(\mathrm{p}=0.05)$.

Lastly, the number of patent teeth were compared between the $\mathrm{BC}$ and traditional gutta percha as well as the XP Shaper and TRUShape file groups. Pearson's chi-square was used to determine whether there is an association between type of gutta percha or type of file and patency at $(\mathrm{p}=$ $0.05)$. 


\section{Chapter IV}

\section{Results}

\section{Kruskal Wallis comparing all 4 groups}

There is evidence that mean percentage of volume remaining $(\mathbf{p}<\mathbf{0 . 0 0 0 1})$ and mean percentage of surface area remaining $(\mathbf{p}=\mathbf{0 . 0 0 0 4})$ differs between the groups. For both the $\%$ of volume remaining and \% of surface area remaining, the BC / XP group was significantly different from the other 3 groups. This group was found to have a significantly higher mean percentage of volume and surface area remaining than the other groups.

Table 5: Mean percentage of volume and surface area remaining

\begin{tabular}{|l|c|c|c|c|}
\hline & BC / XP & BC / TS & TGP / XP & TGP / TS \\
\hline $\begin{array}{l}\% \text { of volume } \\
\text { remaining }\left(\mathrm{mm}^{3}\right)\end{array}$ & $33.98 \pm 5.28^{\mathrm{a}}$ & $10.85 \pm 2.48^{\mathrm{b}}$ & $12.41 \pm 2.39^{\mathrm{b}}$ & $3.39 \pm 0.85^{\mathrm{b}}$ \\
\hline $\begin{array}{l}\% \text { of surface area } \\
\text { remaining }\left(\mathrm{mm}^{2}\right)\end{array}$ & $61.97 \pm 7.17^{\mathrm{a}}$ & $34.02 \pm 6.49^{\mathrm{b}}$ & $30.83 \pm 3.96^{\mathrm{b}}$ & $16.38 \pm 3.21^{\mathrm{b}}$ \\
\hline
\end{tabular}

$\mathrm{BC}=$ bioceramic, TGP $=$ traditional gutta percha, $\mathrm{XP}=\mathrm{XP}$ Shaper file, TRUShape $=$ TRUShape file; Data shown as mean $\pm \mathrm{SEM} ; \mathrm{n}=10$ for each group. Different superscript letters indicate statistically significant differences between groups.

Table 6: Bonferroni adjusted p-values for the pairwise comparison

\begin{tabular}{|c|c|c|}
\hline Comparison & Surface Area p-value & Volume p-value \\
\hline TGP / TS vs TGP / XP & 0.4224 & 0.3135 \\
\hline TGP / TS vs BC / TS & 0.1737 & 0.6346 \\
\hline BC / XP vs BC / TS & $\mathbf{0 . 0 0 5 6}$ & $<\mathbf{0 . 0 0 0 1}$ \\
\hline BC / XP vs TGP / XP & $\mathbf{0 . 0 0 1 7}$ & $\mathbf{0 . 0 0 0 2}$ \\
\hline
\end{tabular}

\section{Summary of Bonferroni adjustment}

1) TGP / TS is not different than TGP / XP (Compares XP to TS within TGP)

2) TGP / TS is not different than BC / TS (Compares TGP to BC within TS)

3) $\mathrm{BC}$ / XP is significantly different than BC / TS (Compares XP to TS within BC)

4) BC / XP is significantly different than TGP / XP (Compares BC and TGP within XP) 


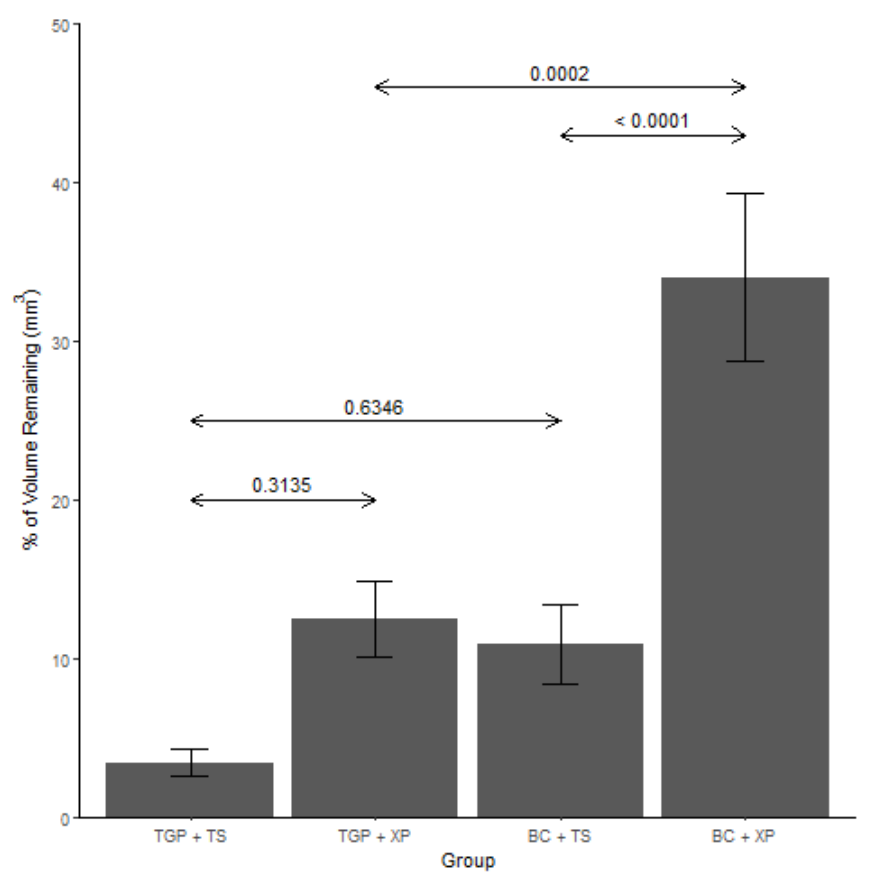

Figure 31: Pairwise comparison of \% volume remaining for groups tested with Bonferroni adjustment

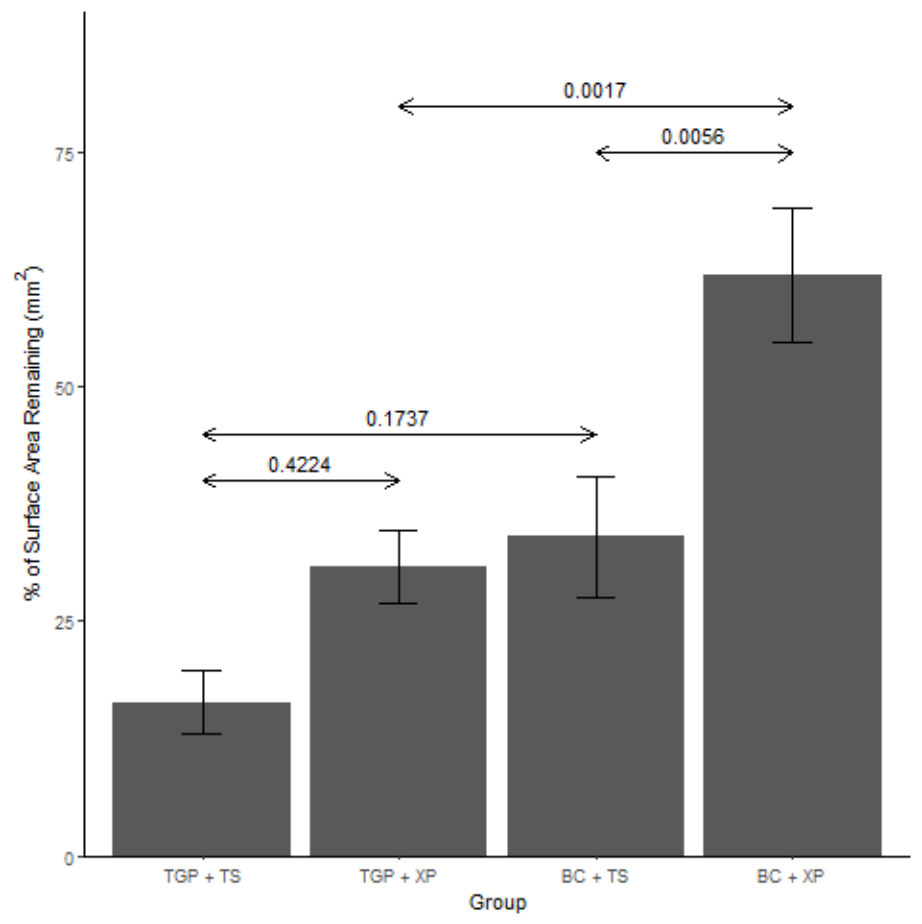

Figure 32: Pairwise comparison of $\%$ surface area remaining for groups tested with the Bonferroni adjustment 


\section{Mann Whitney U comparing Bioceramic Gutta Percha to Traditional Gutta Percha}

The mean percentage of volume remaining $(\mathbf{p}=\mathbf{0 . 0 0 4 3})$ and surface area remaining $(\mathbf{p}=\mathbf{0 . 0 0 4 3})$ both significantly differed between the bioceramic and traditional gutta percha, independent of the type of file used. The mean percentage of volume remaining for all $\mathrm{BC}$ gutta percha was $22.42 \pm 3.88 \%$ compared to $7.90 \pm 1.61 \%$ for traditional gutta percha. Likewise, the mean percentage of surface area remaining was also lower for the TGP groups at $23.61 \pm 3.01 \%$ compared to $48.00 \pm 5.69 \%$ for the $\mathrm{BC}$ groups.

Table 7: Mean percentage of volume and surface area remaining

\begin{tabular}{|c|c|c|}
\hline & BC & TGP \\
\hline $\begin{array}{c}\text { \% of volume } \\
\text { remaining }\left(\mathrm{mm}^{3}\right)\end{array}$ & $22.42 \pm 3.88^{\mathrm{a}}$ & $7.90 \pm 1.61^{\mathrm{b}}$ \\
\hline $\begin{array}{c}\text { \% of surface area } \\
\text { remaining }\left(\mathrm{mm}^{2}\right)\end{array}$ & $48.00 \pm 5.69^{\mathrm{a}}$ & $23.6 \pm 3.01^{\mathrm{b}}$ \\
\hline
\end{tabular}

$\mathrm{BC}=$ bioceramic, $\mathrm{TGP}=$ traditional gutta percha

Data shown as mean $+/$ SEM; $\mathrm{n}=10$ for each group. Different superscript letters indicate statistically significant differences.

\section{Mann Whitney U comparing XP Shaper to TRUShape}

Significant differences were also found when comparing the XP file to the TS file for both the mean percentage of volume remaining $(\mathbf{p}=\mathbf{0 . 0 0 0 6})$ and surface area remaining $(\mathbf{p}=\mathbf{0 . 0 0 5 2})$, independent of the type of gutta percha used. The mean percentage of volume remaining for all XP files was $23.20 \pm 3.75 \%$ compared to $7.12 \pm 1.54 \%$ for TS files. The mean percentage of surface area remaining was also lower for TS files at $25.20 \pm 4.08 \%$ compared to $46.40 \pm 5.35 \%$ for the XP files.

Table 8: Mean percentage of volume and surface area remaining

\begin{tabular}{|c|c|c|}
\hline & XP & TS \\
\hline $\begin{array}{c}\text { \% of volume } \\
\text { remaining }\left(\mathrm{mm}^{3}\right)\end{array}$ & $23.20 \pm 3.75^{\mathrm{a}}$ & $7.12 \pm 1.54^{\mathrm{b}}$ \\
\hline $\begin{array}{c}\text { \% of surface area } \\
\text { remaining }\left(\mathrm{mm}^{2}\right)\end{array}$ & $46.40 \pm 5.35^{\mathrm{a}}$ & $22.20 \pm 4.08^{\mathrm{b}}$ \\
\hline
\end{tabular}

$$
\mathrm{XP}=\mathrm{XP} \text { Shaper file, TS }=\text { TRUShape file }
$$

Data shown as mean $+/$ SEM; $\mathrm{n}=10$ for each group. Different superscript letters indicate statistically significant differences. 


\section{Canal Patency}

There was found to be an association between type of gutta percha and patency, $\chi^{2}(1)=6.46, \mathbf{p}=$ $\mathbf{0 . 0 1 1 0} .65 \%$ of the teeth in the TGP group were patent compared to only $25 \%$ in the BC group.

Table 9: Percentage of patent canals between gutta percha groups

\begin{tabular}{|c|c|c|}
\hline & TGP & BC \\
\hline $\begin{array}{c}\% \text { of patent } \\
\text { canals }\end{array}$ & $65 \%^{\mathrm{a}}$ & $25 \%{ }^{\mathrm{b}}$ \\
\hline
\end{tabular}

$\mathrm{BC}=$ bioceramic, $\mathrm{TGP}=$ traditional gutta percha

Different superscript letters indicate statistically significant differences.

There was insufficient evidence, $\chi^{2}(1)=3.64, \mathbf{p}=\mathbf{0 . 0 5 6 5}$ of a significant statistical association between type of file used and patency.

Although with a $\mathrm{p}$ value equal to 0.0565 , the association appears to be strong with $30 \%$ of the teeth in the XP group patent compared to $60 \%$ in the TS group.

Overall, canal patency was able to be achieved in only 55\% of the roots, independent of the type of file or gutta percha used (Table 2). 


\section{Discussion}

Clinicians have several goals in mind when completing endodontic retreatments. Several of these goals include complete removal of filling material in root canals, regaining canal patency and eradication of bacterial contamination that could result in recurrent or persistent apical periodontitis (89 - 92). The purpose of this study was to determine the efficacy of two NiTi files recently introduced to the market, Brasseler XP Shaper and Dentsply TRUShape, as the primary retreatment files when removing single cone obturated mandibular first molar mesial root canals with traditional gutta percha and bioceramic sealer compared to bioceramic coated gutta percha and bioceramic sealer.

The mesial root of mandibular molars was selected as the root of interest due to complexity of the root canals it contains. These canals often contain curvatures and anastomoses that 2 dimensional radiographs do not detect $(93,94)$. These features cause the retreatment of mandibular first molars to be somewhat challenging, even for the experienced clinicians. The mandibular first molar is also often one of the most common teeth referred to endodontic private practices and residency programs for retreatments. These factors provided the basis for the use of the mesial root of mandibular first molars for this study.

In our study, each tooth was radiographed in a bucco-lingual orientation with a digital sensor to determine the canal patency and the overall curvature of the roots. For consistency purposes with relation to instrumentation, obturation, and retreatability difficulty, only mesial roots with less than 40 degrees of canal curvature and have complete formation of its root apices were selected (87). To maintain consistency between the sample groups, an equal number of internal root canal structure was selected. Each group in the study contained six mesial roots with two orifices and two separate apical foramina and four mesial roots with two orifices and one apical foramen according to Vertucci's classification system of root canal anatomy (88). While it was impossible for all roots to contain the same canal intricacies and length, a mean amount of residual filling material left would not be able to be compared. Instead, the percentage change in residual volume and surface area, of residual filling materials and the ability to regain patency was compared to canals immediately after obturation for statistical analysis.

Residual filling analysis is not new to endodontic research, as numerous authors have published studies comparing different files and instruments used to remove root canal filling material (78, 95 - 99). Historically, these studies were analyzed with 2-dimensional radiographs, weights of the residual filling materials, or sectioning of the roots and examined under endodontic microscopes $(96,97)$. The problem with these methods are numerous. First, $2-$ dimensional imaging does not accurately depict the full story in a 3-dimensional object $(98,99)$. Secondly, mechanical inspection by weight or sectioning can be problematic due to the risk of damage to the sample or loss of material being evaluated (100).

In the last decade, we have seen an increase in the use of 3-dimensional micro-computed tomography as a research vehicle to assess changes in teeth. This method has many advantages over the previous 2D evaluation. Micro-CT analysis allows a researcher to accurately determine the measurements and changes of root canal anatomy in a non-destructive manner $(102,103) .3 \mathrm{D}$ micro-CT is now the standard evaluation tool in endodontic research and has proven to be the most accurate means to quantify research variables such as volumetric change $(85,86)$.

The techniques used for the retreatment with XP Shaper and TRUShape files in our study were not reported in either file manufacturer's DFU. However, Brasseler USA recently published a video showing the use of the XP Shaper file retreating an acrylic maxillary first molar filled 
with BC Sealer and bioceramic gutta percha (21). This video, along with discussion with Brasseler representatives were the basis of this study using XP Shaper file as a primary retreatment instrument.

While the TRUShape file does not have any documentation or videos from its manufacturer similar to Brasseler's video indicating its use as a retreatment file, there was one published study that compared the TRUShape file to a reciprocating NiTi instrument, Reciproc, in regard to the removal of single cone filled mandibular canals with BC Sealer (103). The protocol used in Siqueira Zuolo's research provided a guide for the present study but it was determined not applicable because the operating speed of the rotary motor was not increased to a speed commonly used for NiTi rotary retreatment procedures. At a speed of 300 RPM used in Siqueira Zuolo's study, a warming of the gutta percha to allow instrument penetration into the gutta percha would not occur, therefore, we developed our own protocol based on our clinical experience with the file and with a pilot study.

The pilot study consisted of two mandibular anterior central incisors which were both instrumented to the same apical diameter and obturated with bioceramic sealer and single cone gutta percha. We then completed an initial micro-CT scan followed by the removal of the filling material according to our "plan for study protocol" for each respective file. Upon successful removal of the filling material, a post filling material micro-CT scan was recorded. This pilot study allowed us to test our technique of using the XP Shaper and TRUShape files as primary retreatment instruments.

The results of the present study indicate that the XP Shaper file is most likely not suitable as a primary retreatment instrument when bioceramic sealer is used in combination with a bioceramic coated gutta percha because this combination left significantly more filling material behind in the canals than any other group tested. The file also left significantly more residual material when directly compared to TRUShape, independent of the type of gutta percha used. At this time, our study is the only one available testing the XP Shaper's efficacy as a primary retreatment instrument. However, there are two recently published micro-CT studies in the Journal of Endodontics that tested the file's ability to clean and shape initial root canals. One study used mandibular central incisors and compared the efficacy of the XP Shaper to that of fixed tapered file, Vortex Blue (Dentsply). The results showed that XP Shaper significantly increased the canal volume, surface area, and the amount of dentin removed and had significantly less non-contacted walls compared with Vortex Blue. This study shows that the file does have the ability to adapt to the anatomy of the root canal space better than a standard tapered file (17). Another study compared the efficacy of the XP Shaper, TRUShape, and the Self-Adjusting File (SAF) in distal canals of freshly extracted vital mandibular molars. The author found that there was no statistical difference between the three files in relation to the amount of unprepared surface area remaining, except for the apical $4 \mathrm{~mm}$ of the root canal. In the last $4 \mathrm{~mm}$, the XP Shaper file was significantly better at cleaning and shaping than that of the SAF file, but equally as effective as the TRUShape file in the same area (104). While neither of these studies directly correlate to our current research of obturation material removal, it does demonstrate the superior effectiveness of files that are able to adapt to the radicular canal irregularities better than that of a standard taper file.

Similar to XP Shaper, the available research on the TRUShape file as a retreatment device is sparse. Our study shows that the TRUShape file significantly outperformed the XP Shaper, independent of the type of gutta percha used. These results differ from the one other study that tests TRUShape's efficacy as a retreatment instrument. In that study, it was found that 
TRUShape left a similar amount of residual material compared to the reciprocating instrument, Reciproc, in extracted mandibular canines. However, when looking closer at their results, it is determined that their specific group of TRUShape / BC Sealer used with traditional single cone gutta percha shows results in similar percentage of filling material remaining in our study with the same file and gutta percha combination group, TS / TGP. Variability in results may be due to the teeth used in each respective study and their novel protocol for using TRUShape file. Failure to use a higher speed used in their rotary hand piece above 900 RPM, whereas we used 900 RPM so it may more effectively warm the gutta percha and make removal more efficient (105).

This study also evaluated the ability of bioceramic sealer, specifically, BC Sealer, in combination with either bioceramic coated gutta percha compared to traditional gutta percha. The groups filled with bioceramic gutta percha left significantly more material in the canals than did the groups with traditional gutta percha. To the best of our knowledge there are no bioceramic gutta percha studies available that test the bond strength or removal of the material from root canals so no comparison can be made to the results in our study. There is a recent study available that compares the combination of bioceramic sealer with bioceramic gutta percha or with traditional gutta percha in relation to the presence of voids in the interface between gutta percha and the sealer. The study concluded that there was no advantage of using both bioceramic coated gutta percha with bioceramic sealers since the group obturated with single bioceramic coated cones with bioceramic sealer had more voids compared to groups filled with traditional gutta percha and bioceramic sealer (67). While this does not specifically speak to the variable tested in our group, it does show that the sealability may be compromised compared to the manufacturer's claims of a "monobloc" achieved by the chemical and mechanical bonding to both dentin and the bioceramic gutta percha to allow for a 3D bonded obturation with no shrinkage (65).

Regardless of the type of gutta percha or file used in our study, it seems that the use of a bioceramic sealer did have an effect on the ability to regain patency. While the type of sealer used in our study was not varied between groups, previous studies have shown that retreatment of roots sealed with bioceramic sealer may be more difficult to retreat than other resin and zinc oxide eugenol sealed canals. In our study only 22 of 40 roots, $55 \%$, were able to successfully regain canal patency with significantly more mesial roots regaining patency in the traditional non-coated gutta percha, $65 \%$, compared to the bioceramic coated gutta percha, $25 \%$. Hess et al reported similar canal patency results in their study comparing bioceramic sealer and single cone obturation. In their study, roots filled with bioceramic sealer and gutta percha to their designated working length were able to regain canal patency in $80 \%$ of the samples whereas samples filled 2 $\mathrm{mm}$ short of their working length only regained patency $30 \%$ of the time (33). This difference could be due to the possible formation of the hydroxyapatite precipitate when the calcium silicate reacts with the environmental moisture. These results are in direct contrast to that of Kim et al. They compared the retreatment efficacy of bioceramic sealer compared to that of resin based sealers and found no difference in the ability to remove these sealers when used with traditional gutta percha. They were also able to achieve canal patency in $100 \%$ of their samples (63). A possible reason for the study's discrepancy in results is that Kim use single rooted straight canals whereas Hess used mesial buccal roots of the mandibular first molar.

Similar to other studies completed on the efficacy of different retreatment techniques, this study also left residual filling material in the canals (1- 4, 95 - 100). While the goal of endodontic retreats is to remove all of the previously placed material, this study along with numerous other 
studies show that multiple instruments or medicaments may be needed in order to remove a larger percentage of filling material.

Time was not a variable tested in our study. In some retreatment studies testing instruments' efficacy, the amount of time to reach working length or to achieve canal patency were recorded and analyzed for statistical significance. In our study, we took as much time needed to reach either working length or canal patency. If the advancement of a file was not possible and no debris was observed on the file's flutes, we terminated the test on that respective canal and recorded it as "not patent".

Observation of the retreated micro-CT images showed that some canals in the mesial roots had nearly complete removal of filling material from one canal while the second canal in the root had significantly more material remaining. We did not make an effort to analyze the amount of material remaining between the mesio-lingual and mesio-buccal canals, although further analysis could be completed on the data. While a new file was used for each root, a new file was not used for each canal in each root. A possible reason for one canal to have more residual filling material than the other could be the dulling of the instruments tip or cutting flutes after its initial use in the first canal. Further investigation would be needed to test this hypothesis.

Solvents to aid in the softening of gutta percha were not used in this protocol in attempt to standardize the experimental designs that follow similar protocol in other retreatment studies so the results can be compared. Some clinicians believe in the completion of retreatments without the use of solvents due to the potential carcinogenic nature of the solvents; incompatibility of the solvents with rubber dam materials commonly used for isolation during root canal therapy, and the thin layer of softened gutta percha that forms along the canal walls makes ultimate removal difficult and tedious $(97,106)$. Despite the possible downsides of solvent properties, many clinicians continue to favor them to remove root canal fillings. Future studies should incorporate solvents and files as variables in the retreatment procedure.

While the specifics of the technique were considered novel for this study, modifications could be made such as; specific instrumentation sequence, implementation of a glide path with a hand file, removal of the coronal filling material with a Gates Glidden drills, different brands of gutta percha, addition of heat. Any of these modifications could be implemented into future studies in hopes of perfecting the technique with 3D motion files being utilized as primary instruments for root canal filling material removal.

In a controlled setting like our testing protocol, we are able to know exactly what type of gutta percha and sealer are being used. In a real-world setting, a clinician completing an endodontic retreat often does not know the specifics of the type of material used during the obturation of the canals unless he or she completed the initial treatment. With that said, further testing of the files in this study on different styles of obturation methods and sealers could be completed to determine if a specific combination would lend itself better suited as a material to be removed by a primary 3D motion NiTi file. 


\section{Chapter V}

\section{Conclusion}

All null hypotheses were rejected. Neither novel primary retreat file was able to completely remove the filling material from the mesial roots of mandibular molars or regain canal patency in every root, independent of the type of gutta percha or file used as a primary instrument. The results of this study indicated that the XP Shaper file is not particularly suitable as the primary instrument in removal of root canal filling material, especially that of bioceramic in nature. However, the TRUShape file was significantly more effective as a primary retreatment file, independent of the type of gutta percha used. The results of this study also show that the use of a bioceramic sealer in combination with a bioceramic coated gutta percha may make the retreatment process more difficult as the group filled with traditional gutta percha was able to regain patency significantly more often than the bioceramic coated gutta percha. Independent of the type of gutta percha used, bioceramic sealer alone may make it more difficult to achieve canal patency with only $45 \%$ of the total samples able to regain canal patency. Further tests should be conducted with the same groups to determine any significant difference in the amount of residual material in this study compared to the amount left when solvents are introduced. 


\section{Works Citied}

1. Imura N, Zuolo ML, Ferreira MO, Novo NF. Effectiveness of the Canal Finder and hand instrumentation in removal of gutta-percha root fillings during root canal retreatment. International endodontic journal. 1996 Nov 1;29(6):382-6.

2. Takahashi CM, Cunha RS, De Martin AS, Fontana CE, Silveira CF, da Silveira Bueno CE. In vitro evaluation of the effectiveness of ProTaper universal rotary retreatment system for guttapercha removal with or without a solvent. Journal of Endodontics. 2009 Nov 30;35(11):1580-3.

3. Bramante CM, Fidelis NS, Assumpção TS, Bernardineli N, Garcia RB, Bramante AS, de Moraes IG. Heat release, time required, and cleaning ability of MTwo R and ProTaper universal retreatment systems in the removal of filling material. Journal of Endodontics. 2010 Nov 30;36(11):1870-3.

4. Rödig T, Kupis J, Konietschke F, Dullin C, Drebenstedt S, Hülsmann M. Comparison of hand and rotary instrumentation for removing gutta-percha from previously treated curved root canals: a microcomputed tomography study. International endodontic journal. 2014 Feb 1;47(2):173-82.

5. Rôças IN, Siqueira JF. Characterization of microbiota of root canal-treated teeth with posttreatment disease. Journal of clinical microbiology. 2012 May 1;50(5):1721-4.

6. Ricucci D, Siqueira JF, Bate AL, Ford TR. Histologic investigation of root canal-treated teeth with apical periodontitis: a retrospective study from twenty-four patients. Journal of Endodontics. 2009 Apr 30;35(4):493-502.

7. Gambarini G, Piasecki L, Schianchi G, Di Nardo D, Miccoli G, Al Sudani D, Di Giorgio R, Testarelli L. In vitro evaluation of carrier based obturation technique: a CBCT study. Annali di stomatologia. 2016 Jan;7(1-2):11.

8. Neuhaus KW, Schick A, Lussi A. Apical filling characteristics of carrier-based techniques vs. single cone technique in curved root canals. Clinical oral investigations. 2016 Sep 1;20(7):16317.

9. Brasseler USA. Available at: http://brasselerusa.com/wp-content/files/IFU0018\%20Brasseler\%20USA\%20ES\%20BC\%20Sealer\%20IFU\%20REV\%20B.pdf. Accessed November 15, 2017.

10. Wang Z. Bioceramic materials in endodontics. Endodontic Topics. 2015 May 1;32(1):3-0.

11. Hargreaves KM, Berman LH. Cohen's pathways of the pulp. Elsevier Health Sciences; 2015. $349-383$.

12. Hülsmann M, Bluhm V. Efficacy, cleaning ability and safety of different rotary NiTi instruments in root canal retreatment. International endodontic journal. 2004 Jul 1;37(7):468-76. 
13. Topçuoğlu HS, Aktı A, Tuncay Ö, Dinçer AN, Düzgün S, Topçuoğlu G. Evaluation of debris extruded apically during the removal of root canal filling material using ProTaper, D-RaCe, and R-Endo rotary nickel-titanium retreatment instruments and hand files. Journal of endodontics. 2014 Dec 31;40(12):2066-9.

14. Özyürek T, Demiryürek EÖ. Efficacy of different nickel-titanium instruments in removing gutta-percha during root canal retreatment. Journal of endodontics. 2016 Apr 30;42(4):646-9.

15. Barbizam JV, Fariniuk LF, Marchesan MA, Pecora JD, Sousa-Neto MD. Effectiveness of manual and rotary instrumentation techniques for cleaning flattened root canals. Journal of endodontics. 2002 May 31;28(5):365-6.

16. Peters OA. Current challenges and concepts in the preparation of root canal systems: a review. Journal of endodontics. 2004 Aug 31;30(8):559-67.

17. Azim AA, Piasecki L, da Silva Neto UX, Cruz AT, Azim KA. XP Shaper, A Novel Adaptive Core Rotary Instrument: Micro-computed Tomographic Analysis of Its Shaping Abilities. Journal of Endodontics. 2017 Sep 1;43(9):1532-8.

18. Niemi TK, Marchesan MA, Lloyd A, Seltzer RJ. Effect of Instrument Design and Access Outlines on the Removal of Root Canal Obturation Materials in Oval-shaped Canals. Journal of endodontics. 2016 Oct 31;42(10):1550-4.

19. Alves FR, Marceliano-Alves MF, Sousa JC, Silveira SB, Provenzano JC, Siqueira JF. Removal of root canal fillings in curved canals using either reciprocating single-or rotary multiinstrument systems and a supplementary step with the XP-Endo Finisher. Journal of endodontics. 2016 Jul 31;42(7):1114-9.

20. Silva EJ, Belladonna FG, Zuolo AS, Rodrigues E, Ehrhardt IC, Souza EM, De-Deus G. Effectiveness of XP-endo Finisher and XP-endo Finisher $\mathrm{R}$ in removing root filling remnants: a micro-CT study. International Endodontic Journal. 2017 May 3.

21. Brasseler USA. https://youtu.be/uQpVQHfJ7po Accessed November 15, 2017

22. De Pablo ÓV, Estevez R, Sánchez MP, Heilborn C, Cohenca N. Root anatomy and canal configuration of the permanent mandibular first molar: a systematic review. Journal of Endodontics. 2010 Dec 31;36(12):1919-31.

23. Kartal N, Cimilli HK. The degrees and configurations of mesial canal curvatures of mandibular first molars. Journal of endodontics. 1997 Jun 1;23(6):358-62.

24. Iqbal M, Chan S, Ku J. Relative frequency of teeth needing conventional and surgical endodontic treatment in patients treated at a graduate endodontic clinic - a Penn Endo database study. Oral Surgery, Oral Medicine, Oral Pathology, Oral Radiology, and Endodontology. 2008 Jul 31;106(1):e62-7. 
25. Ingle JI. Ingle's endodontics 6. PMPH-USA; 2008. 1053 - 1066.

26. Gordon MP, Love RM, Chandler NP. An evaluation of. 06 tapered gutta-percha cones for filling of. 06 taper prepared curved root canals. International endodontic journal. $2005 \mathrm{Feb}$ $1 ; 38(2): 87-96$.

27. Iglecias EF, Freire LG, de Miranda Candeiro GT, Dos Santos M, Antoniazzi JH, Gavini G. Presence of Voids after Continuous Wave of Condensation and Single-cone Obturation in Mandibular Molars: A Micro-computed Tomography Analysis. Journal of endodontics. 2017 Apr 30;43(4):638-42.

28. Alshehri M, Alamri HM, Alshwaimi E, Kujan O. Micro-computed tomographic assessment of quality of obturation in the apical third with continuous wave vertical compaction and single match taper sized cone obturation techniques. Scanning. 2016 Jul 1;38(4):352-6.

29. Robberecht L, Colard T, Claisse-Crinquette A. Qualitative evaluation of two endodontic obturation techniques: tapered single-cone method versus warm vertical condensation and injection system an in vitro study. Journal of oral science. 2012;54(1):99-104.

30. Tasdemir T, Yesilyurt C, Ceyhanli KT, Celik D, Er K. Evaluation of apical filling after root canal filling by 2 different techniques. Journal of the Canadian Dental Association. 2009 Apr $1 ; 75(3)$.

31. Jeong JW, DeGraft-Johnson A, Dorn SO, Di Fiore PM. Dentinal Tubule Penetration of a Calcium Silicate-based Root Canal Sealer with Different Obturation Methods. Journal of endodontics. 2017 Apr 30;43(4):633-7.

32. Hegde V, Arora S. Sealing ability of three hydrophilic single-cone obturation systems: An in vitro glucose leakage study. Contemporary clinical dentistry. 2015 Mar;6(Suppl 1):S86.

33. Hess D, Solomon E, Spears R, He J. Retreatability of a bioceramic root canal sealing material. Journal of endodontics. 2011 Nov 30;37(11):1547-9.

34. Lottanti S, Tauböck TT, Zehnder M. Shrinkage of backfill gutta-percha upon cooling. Journal of endodontics. 2014 May 31;40(5):721-4.

35. Haapasalo M, Endal U, Zandi H, Coil JM. Eradication of endodontic infection by instrumentation and irrigation solutions. Endodontic topics. 2005 Mar 1;10(1):77-102.

36. Darvell BW, Wu RC. "MTA" - an hydraulic silicate cement: review update and setting reaction. Dental Materials. 2011 May 31;27(5):407-22.

37. Ma J, Shen Y, Stojicic S, Haapasalo M. Biocompatibility of two novel root repair materials. Journal of endodontics. 2011 Jun 30;37(6):793-8. 
38. Koubi G, Colon P, Franquin JC, Hartmann A, Richard G, Faure MO, Lambert G. Clinical evaluation of the performance and safety of a new dentine substitute, Biodentine, in the restoration of posterior teeth - a prospective study. Clinical oral investigations. 2013 Jan $1 ; 17(1): 243-9$.

39. Veljović D, Čolić M, Kojić V, Bogdanović G, Kojić Z, Banjac A, Palcevskis E, Petrović R, Janaćković D. The effect of grain size on the biocompatibility, cell-materials interface, and mechanical properties of microwave-sintered bioceramics. Journal of Biomedical Materials Research Part A. 2012 Nov 1;100(11):3059-70.

40. Atmeh AR, Chong EZ, Richard G, Festy F, Watson TF. Dentin-cement interfacial interaction: calcium silicates and polyalkenoates. Journal of Dental Research. 2012 May;91(5):454-9.

41. Koch KA, Brave DG. Bioceramics, part I: the clinician's viewpoint. Dentistry today. 2012 Jan;31(1):130.

42. Reyes-Carmona JF, Felippe MS, Felippe WT. Biomineralization ability and interaction of mineral trioxide aggregate and white portland cement with dentin in a phosphate-containing fluid. Journal of Endodontics. 2009 May 31;35(5):731-6.

43. Loushine BA, Bryan TE, Looney SW, Gillen BM, Loushine RJ, Weller RN, Pashley DH, Tay FR. Setting properties and cytotoxicity evaluation of a premixed bioceramic root canal sealer. Journal of endodontics. 2011 May 31;37(5):673-7.

44. Yang Q, Troczynski T, Liu DM. Influence of apatite seeds on the synthesis of calcium phosphate cement. Biomaterials. 2002 Jul 31;23(13):2751-60.

45. Celikten B, Uzuntas CF, Orhan AI, Orhan K, Tufenkci P, Kursun S, Demiralp KÖ. Evaluation of root canal sealer filling quality using a single-cone technique in oval shaped canals: An In vitro Micro-CT study. Scanning. 2016 Mar 1;38(2):133-40.

46. Guinesi AS, Faria G, Tanomaru-Filho M, Bonetti-Filho I. Influence of sealer placement technique on the quality of root canal filling by lateral compaction or single cone. Brazilian dental journal. 2014;25(2):117-22.

47. Nagas E, Uyanik MO, Eymirli A, Cehreli ZC, Vallittu PK, Lassila LV, Durmaz V. Dentin moisture conditions affect the adhesion of root canal sealers. Journal of Endodontics. 2012 Feb $29 ; 38(2): 240-4$.

48. DeLong C, He J, Woodmansey KF. The effect of obturation technique on the push-out bond strength of calcium silicate sealers. Journal of endodontics. 2015 Mar 31;41(3):385-8.

49. Sagsen B, Ustün Y, Demirbuga S, Pala K. Push-out bond strength of two new calcium silicate-based endodontic sealers to root canal dentine. International endodontic journal. 2011 Dec 1;44(12):1088-91. 
50. Ersahan S, Aydin C. Dislocation resistance of iRoot SP, a calcium silicate-based sealer, from radicular dentine. Journal of endodontics. 2010 Dec 31;36(12):2000-2.

51. Özcan E, Capar ID, Çetin AR, Tunçdemir AR, Aydınbelge HA. The effect of calcium silicate-based sealer on the push-out bond strength of fibre posts. Australian dental journal. 2012 Jun 1;57(2):166-70.

52. Amin SA, Seyam RS, El-Samman MA. The effect of prior calcium hydroxide intracanal placement on the bond strength of two calcium silicate-based and an epoxy resin-based endodontic sealer. Journal of endodontics. 2012 May 31;38(5):696-9.

53. Borges RP, Sousa-Neto MD, Versiani MA, Rached-Júnior FA, De-Deus G, Miranda CE, Pécora JD. Changes in the surface of four calcium silicate-containing endodontic materials and an epoxy resin-based sealer after a solubility test. International endodontic journal. 2012 May 1;45(5):419-28.

54. Ersahan S, Aydin C. Solubility and apical sealing characteristics of a new calcium silicatebased root canal sealer in comparison to calcium hydroxide-, methacrylate resin-and epoxy resinbased sealers. Acta Odontologica Scandinavica. 2013 Jan 1;71(3-4):857-62.

55. Willershausen I, Callaway A, Briseño B, Willershausen B. In vitro analysis of the cytotoxicity and the antimicrobial effect of four endodontic sealers. Head \& face medicine. 2011 Aug 10;7(1):15.

56. Mukhtar-Fayyad D. Cytocompatibility of new bioceramic-based materials on human fibroblast cells (MRC-5). Oral Surgery, Oral Medicine, Oral Pathology, Oral Radiology, and Endodontology. 2011 Dec 31;112(6):e137-42.

57. Zoufan K, Jiang J, Komabayashi T, Wang YH, Safavi KE, Zhu Q. Cytotoxicity evaluation of Gutta flow and endo sequence BC sealers. Oral Surgery, Oral Medicine, Oral Pathology, Oral Radiology, and Endodontology. 2011 Nov 30;112(5):657-61.

58. Zhang S, Yang X, Fan M. BioAggregate and iRoot BP Plus optimize the proliferation and mineralization ability of human dental pulp cells. International endodontic journal. 2013 Oct 1;46(10):923-9.

59. da Silva EJ, Zaia AA, Peters OA. Cytocompatibility of calcium silicate-based sealers in a three-dimensional cell culture model. Clinical oral investigations. 2016 Jul 26:1-6.

60. Scelza MZ, Linhares AB, Da Silva LE, Granjeiro JM, Alves GG. A multiparametric assay to compare the cytotoxicity of endodontic sealers with primary human osteoblasts. International Endodontic Journal. 2012 Jan 1;45(1):12-8.

61. Wang Z, Shen Y, Haapasalo M. Dentin extends the antibacterial effect of endodontic sealers against Enterococcus faecalis biofilms. Journal of endodontics. 2014 Apr 30;40(4):505-8. 
62. Oltra E, Cox TC, LaCourse MR, Johnson JD, Paranjpe A. Retreatability of two endodontic sealers, EndoSequence BC Sealer and AH Plus: a micro-computed tomographic comparison. Restorative dentistry \& endodontics. 2017 Feb 1;42(1):19-26.

63. Kim H, Kim E, Lee SJ, Shin SJ. Comparisons of the Retreatment Efficacy of Calcium Silicate and Epoxy Resin-based Sealers and Residual Sealer in Dentinal Tubules. Journal of endodontics. 2015 Dec 31;41(12):2025-30.

64. Ersev H, Yılmaz B, Dinçol ME, Dağlaroğlu R. The efficacy of ProTaper Universal rotary retreatment instrumentation to remove single gutta-percha cones cemented with several endodontic sealers. International endodontic journal. 2012 Aug 1;45(8):756-62.

65. Brasseler USA: BC Points: https://brasselerusadental.com/products/bc-points/ Accessed on November 15, 2017.

66. Ghoneim AG, Lutfy RA, Sabet NE, Fayyad DM. Resistance to fracture of roots obturated with novel canal-filling systems. Journal of endodontics. 2011 Nov 30;37(11):1590-2.

67. Eltair M, Pitchika V, Hickel R, Kühnisch J, Diegritz C. Evaluation of the interface between gutta-percha and two types of sealers using scanning electron microscopy (SEM). Clinical Oral Investigations. 2017 Oct 27:1-9.

68. Ricucci D, Siqueira JF. Biofilms and apical periodontitis: study of prevalence and association with clinical and histopathologic findings. Journal of endodontics. 2010 Aug 31;36(8):1277-88.

69. Ricucci D, Siqueira JF, Bate AL, Ford TR. Histologic investigation of root canal-treated teeth with apical periodontitis: a retrospective study from twenty-four patients. Journal of Endodontics. 2009 Apr 30;35(4):493-502.

70. Farzaneh M, Abitbol S, Friedman S. Treatment outcome in endodontics: the Toronto study. Phases I and II: Orthograde retreatment. Journal of Endodontics. 2004 Sep 30;30(9):627-33.

71. de Chevigny C, Dao TT, Basrani BR, Marquis V, Farzaneh M, Abitbol S, Friedman S. Treatment outcome in endodontics: the Toronto study - phases 3 and 4: orthograde retreatment. Journal of Endodontics. 2008 Feb 29;34(2):131-7.

72. Wilcox LR, Krell KV, Madison S, Rittman B. Endodontic retreatment: evaluation of guttapercha and sealer removal and canal reinstrumentation. Journal of Endodontics. 1987 Sep 1;13(9):453-7.

73. Colaco AS, Pai VA. Comparative evaluation of the efficiency of manual and rotary guttapercha removal techniques. Journal of endodontics. 2015 Nov 30;41(11):1871-4.

74. de Azevêdo Rios M, Villela AM, Cunha RS, Velasco RC, De Martin AS, Kato AS, da Silveira Bueno CE. Efficacy of 2 reciprocating systems compared with a rotary retreatment system for gutta-percha removal. Journal of endodontics. 2014 Apr 30;40(4):543-6. 
75. Özyürek T, Demiryürek EÖ. Efficacy of different nickel-titanium instruments in removing gutta-percha during root canal retreatment. Journal of endodontics. 2016 Apr 30;42(4):646-9.

76. Bramante CM, Fidelis NS, Assumpção TS, Bernardineli N, Garcia RB, Bramante AS, de Moraes IG. Heat release, time required, and cleaning ability of MTwo R and ProTaper universal retreatment systems in the removal of filling material. Journal of Endodontics. $2010 \mathrm{Nov}$ 30;36(11):1870-3.

77. Rödig T, Hausdörfer T, Konietschke F, Dullin C, Hahn W, Hülsmann M. Efficacy of D$\mathrm{RaCe}$ and ProTaper Universal Retreatment NiTi instruments and hand files in removing guttapercha from curved root canals-a micro-computed tomography study. International endodontic journal. 2012 Jun 1;45(6):580-9.

78. de Mello JE, Cunha RS, da Silveira Bueno CE, Zuolo ML. Retreatment efficacy of guttapercha removal using a clinical microscope and ultrasonic instruments: part I - an ex vivo study. Oral Surgery, Oral Medicine, Oral Pathology, Oral Radiology, and Endodontology. 2009 Jul 31;108(1):e59-62.

79. Peters OA, Barbakow F, Peters CI. An analysis of endodontic treatment with three nickeltitanium rotary root canal preparation techniques. International endodontic journal. $2004 \mathrm{Dec}$ $1 ; 37(12): 849-59$.

80. Brasseler: XP Shaper: http://xp-3d.com/shaper/ Accessed on November 15, 2017.

81. Dentsply: TruShape:

https://www.dentsply.com/content/dam/dentsply/pim/manufacturer/Endodontics/Glide Path Sh aping/Rotary Reciprocating Files/3D Conforming/TRUShape 3D Conforming Files/TRUSh ape-3D-Conforming-Files-Brochure-2vkhexu-en-1504.pdf

Accessed on November 15, 2017.

82. Guimarães LS, Gomes CC, Marceliano-Alves MF, Cunha RS, Provenzano JC, Siqueira JF. Preparation of Oval-shaped Canals with TRUShape and Reciproc Systems: A Micro-Computed Tomography Study Using Contralateral Premolars. Journal of Endodontics. 2017 Jun 30;43(6):1018-22.

83. Peters OA, Arias A, Paqué F. A micro-computed tomographic assessment of root canal preparation with a novel instrument, TRUShape, in mesial roots of mandibular molars. Journal of endodontics. 2015 Sep 30;41(9):1545-50.

84. de Siqueira Zuolo A, Zuolo ML, da Silveira Bueno CE, Chu R, Cunha RS. Evaluation of the efficacy of TRUShape and Reciproc file systems in the removal of root filling material: an ex vivo micro-computed tomographic study. Journal of endodontics. 2016 Feb 29;42(2):315-9. 
85. Rhodes JS, Ford TR, Lynch JA, Liepins PJ, Curtis RV. Micro-computed tomography: a new tool for experimental endodontology. International Endodontic Journal. 1999 May 1;32(3):16570 .

86. Nielsen RB, Alyassin AM, Peters DD, Carnes DL, Lancaster J. Microcomputed tomography: an advanced system for detailed endodontic research. Journal of endodontics. 1995 Nov $1 ; 21(11): 561-8$.

87. Schneider SW. A comparison of canal preparations in straight and curved root canals. Oral surgery, Oral medicine, Oral pathology. 1971 Aug 31;32(2):271-5.

88. Vertucci FJ. Root canal anatomy of the human permanent teeth. Oral surgery, oral medicine, oral pathology. 1984 Nov 1;58(5):589-99.

89. Torabinejad M, Corr R, Handysides R, Shabahang S. Outcomes of nonsurgical retreatment and endodontic surgery: a systematic review. Journal of endodontics. 2009 Jul 31;35(7):930-7.

90. Stabholz A, Friedman S. Endodontic retreatment - case selection and technique. Part 2: treatment planning for retreatment. Journal of endodontics. 1988 Dec 1;14(12):607-14.

91. Ricucci D, Siqueira JF. Biofilms and apical periodontitis: study of prevalence and association with clinical and histopathologic findings. Journal of endodontics. 2010 Aug 31;36(8):1277-88.

92. Nair PN. On the causes of persistent apical periodontitis: a review. International endodontic journal. 2006 Apr 1;39(4):249-81.

93. De Pablo ÓV, Estevez R, Sánchez MP, Heilborn C, Cohenca N. Root anatomy and canal configuration of the permanent mandibular first molar: a systematic review. Journal of Endodontics. 2010 Dec 31;36(12):1919-31.

94. Kartal N, Cimilli HK. The degrees and configurations of mesial canal curvatures of mandibular first molars. Journal of endodontics. 1997 Jun 1;23(6):358-62.

95. Zuolo AS, Mello JE, Cunha RS, Zuolo ML, Bueno CE. Efficacy of reciprocating and rotary techniques for removing filling material during root canal retreatment. International endodontic journal. 2013 Oct 1;46(10):947-53.

96. de Carvalho Maciel AC, Zaccaro Scelza MF. Efficacy of automated versus hand instrumentation during root canal retreatment: an ex vivo study. International Endodontic Journal. 2006 Oct 1;39(10):779-84.

97. Gu LS, Ling JQ, Wei X, Huang XY. Efficacy of ProTaper Universal rotary retreatment system for gutta-percha removal from root canals. International Endodontic Journal. 2008 Apr 1;41(4):288-95. 
98. Taşdemir T, Er K, Yildirim T, Celik D. Efficacy of three rotary NiTi instruments in removing gutta-percha from root canals. International Endodontic Journal. 2008 Mar $1 ; 41(3): 191-6$.

99. Saad AY, Al-Hadlaq SM, Al-Katheeri NH. Efficacy of two rotary NiTi instruments in the removal of gutta-percha during root canal retreatment. Journal of Endodontics. 2007 Jan 31;33(1):38-41.

100. Kfir A, Tsesis I, Yakirevich E, Matalon S, Abramovitz I. The efficacy of five techniques for removing root filling material: microscopic versus radiographic evaluation. International endodontic journal. 2012 Jan 1;45(1):35-41.

101. Paqué F, Peters OA. Micro-computed tomography evaluation of the preparation of long oval root canals in mandibular molars with the self-adjusting file. Journal of endodontics. 2011 Apr 30;37(4):517-21.

102. Versiani MA, Pécora JD, de Sousa-Neto MD. Flat-oval root canal preparation with selfadjusting file instrument: a micro-computed tomography study. Journal of endodontics. $2011 \mathrm{Jul}$ 31;37(7):1002-7.

103. de Siqueira Zuolo A, Zuolo ML, da Silveira Bueno CE, Chu R, Cunha RS. Evaluation of the efficacy of TRUShape and Reciproc file systems in the removal of root filling material: an ex vivo micro-computed tomographic study. Journal of endodontics. 2016 Feb 29;42(2):315-9.

104. Lacerda MF, Marceliano-Alves MF, Pérez AR, Provenzano JC, Neves MA, Pires FR, Gonçalves LS, Rôças IN, Siqueira Jr JF. Cleaning and Shaping Oval Canals with 3 Instrumentation Systems: A Correlative Micro-computed Tomographic and Histologic Study. Journal of Endodontics. 2017 Sep 23.

105. Ruddle on Retreatment. Directed by Clifford J Ruddle and Advanced Endodontics. Advanced Endodontics, 2004. DVD.

106. Sae-Lim V, Lim BK, Lee HL. Effectiveness of ProFile. 04 taper rotary instruments in endodontic retreatment. Journal of Endodontics. 2000 Feb 29;26(2):100-4. 